\title{
A Youth Perspective: \\ Collaboration for Youth Development within Aotearoa New Zealand
}

\author{
By
}

Amy Lavini

\author{
A thesis \\ submitted to Victoria University of Wellington \\ in fulfilment of the requirements for the degree of \\ Master in Education
}

Victoria University of Wellington

2011 


\section{Acknowledgements}

A brief note of thanks to all those who helped make my accomplishing this work possible:

To my supervisor, Cherie Chu: For your unwavering support and belief in me when I at times could not find it in myself. I have learnt much from you over the last 18 months, perhaps more from your actions than words. Having absolute full reign in every aspect of this study was overwhelming at the best of times but a great and well-needed learning experience. Thank you.

To my husband, Tali: For keeping me on in-spite of my less-lovely times these last couple of years! I truly appreciate your patience and support and hope that I am able to return the favour in your endeavours. Thank you for wanting to help even when there was nothing you could do. Just being here for me means everything.

To my children, Elias and Jaslyn: For being such joyful and flexible children. Elias, a special thanks to you - so much of my success relied upon being able to work around you and you were so co-operative and patient.

To my mum: For always being there when I made last minute arrangements to pop-in and 'unload' before rushing off to appointments. For proof-reading and being supportive all round.

To the rest of my family: For all your support, concern, and interest. It was nice to know that if no-one else cared you all did.

To our extended family - Aunty Rach, Aunty Nga, Aunty Jenna, Aunty Ramari, Aunty Elly, Aunty Crys, Kris and Mu, 'Nelle, Arpege, Awhi, and so on: For being here whenever I had interviews to conduct, deadlines to meet, burdens to share, or just needed time out. Thank you for your love and support towards me and my family.

To the Youth: Those of you who participated in the study, I am especially grateful. Thank you for allowing me into your world and sharing your insights. I admire and respect each of you. There are also many others who have inspired me along the way - I hope to always do right by our young people and campaign for the youth voice to be heard.

Thank you again to you all. 


\begin{abstract}
Collaboration is an increasingly popular approach to addressing the multi-faceted needs of youth-at-risk both within academic literature and government policy in New Zealand. Due to being a relevantly new concept, there is limited evidence in the literature regarding how it is being implemented and whether implementations are successful. There is aparticular gap within the literature regarding the experiences of frontline workers and youth themselves. As youth are the key benefactors of youth services it seems important to understand whether and how they perceive the collaborative approach to be working to assist them in their development. To determine this, the following study explores the experiences of nine youth in New Zealand regarding collaborative processes used by services they have been privy to over recent years. Youth participants came from across New Zealand and altogether have experienced a range of youth interventions, from alternative education to Family Group Conferences, aimed at addressing anti-social and criminal behaviours. Taking a phenomenological approach, the study is carried out using concepts from the framework of Appreciative Inquiry (AI). The use of AI ensured the study was strengths focussed and allowed youth to become active agents rather than subjects of enquiry. Furthermore, it has allowed a positive paradigm for discussing ways to ensure that youth services are better focussed on youth's needs, feelings and understandings. Along with the findings regarding collaboration a common theme arose when youth were invited to share their stories which highlighted further areas for discussion when addressing successful service outcomes. That is, the importance of relationship building.
\end{abstract}




\section{Table of Contents}

Acknowledgements

Abstract

Table of Contents

A Note about the Voice within the Text

Personal Background

Chapter 2: Background to the Study

Purpose

Rationale

Aim of the Study

Research Questions

Significance of the Study

Conceptual Framework

Underlying Assumptions

Limitations

Definitions

A Snapshot of Youth in Aotearoa New Zealand

Chapter 3: Literature Review 
Collaboration

Definitions and Features of Collaboration

Collaboration in Action

Factors for Success and Challenges to Overcome

Contributors to the Collaborative Process

Summary of Literature Review

Chapter 4: Methodology

Method

Rationalisation of the Methodology

Methodological Approach

Participants

Data Collection

Data Analysis

Accountability and Trustworthiness

Consideration of Ethics

Sub-Research Question 1

Sub-Research Question 2

Sub-Research Question 3 
Figure 1 


\section{Chapter 1 Introduction}

While the term 'youth-at-risk' may have negative undertones, it has come about with the growing understanding that due to differing life circumstances and environments some youth have greater needs than others to ensure positive life outcomes. A phrase often found in close proximity to 'youth-at-risk' is 'complex and multi-faceted needs'. That is, that youth deemed 'at-risk' often present with more than one risk-factor effecting their behaviour or predicament. Due to the growing awareness of multiple influences and needs there is an increasing call for holistic approaches to be used addressing them. Collaboration is one such approach that is being discussed both within literature and government policy in New Zealand.

This thesis is an exploration of collaboration from a youth perspective. Good as it is to know that government and professionals are aware of the need for and benefits of collaboration, only those who are supposed to be benefitting from its implementation can identify whether it really helps or is even being applied. The exploration will be achieved through hearing the real experiences of youth who are, or have been involved, in some form of youth development programme in recent years.

To further discuss the reasoning behind this thesis, chapter two looks at the background to the study. This will include a rationale, and an explanation of the purpose, aims and significance of the study. The research questions are also outlined in this chapter and the conceptual framework of Appreciative Inquiry for carrying the research out is introduced in depth. Finally, underlying assumptions, limitations of the study and definitions required for clarification are also included in this chapter.

The third chapter is made up of a literature review that looks at concepts of youth, youth-at-risk, and collaboration. Both youth and collaboration are terms with broad and varying definitions that require an in depth review for assuring a clear understanding of their 
meanings for the purpose of this study. With collaboration still being a reasonably new approach to youth and social services, studies relating to its implementation and effectiveness for both youth and social services are limited. For this reason therefore, along with the academic literature relating to collaborative concepts, examples are given of different ways it is being implemented and defined within government documents and evaluations. The final section of the chapter looks at suggestions for who should be involved in the collaborative process.

The fourth chapter discusses the methodology under which the research was carried out. This chapter includes an explanation of the qualitative research method of phenomenology used for carrying out the exploration and a rationalisation for using this method. Phenomenology goes hand in hand with the Appreciative Inquiry (AI) framework in that it ensures empirical data be gained through hearing the stories of those immediately effected by the collaborative process. Using the AI framework as a basis for interviews further ensures that participants are empowered through the process and not made to feel like subjects of enquiry. Participants and procedure are also discussed in this chapter along with how data will be collected and analysed. Finally, accountability, trustworthiness and ethics are addressed.

The fifth chapter contains the findings of the youth perspective resulting from the interview process. It should be noted that the findings were not as anticipated. While research questions were answered and there were consistencies between the literature and the youth perspective, the more pressing concerns raised by the youth perspective had not previously been appreciated by myself to the degree that they now are.

The sixth and final chapter brings together the findings and the literature previously reviewed in chapter six to addresses both the research questions outlined in chapter two along with an in-depth examination of how the concerns raised by the youth perspective might be addressed. This chapter includes concluding remarks that summarise the study and 
encourages those in a position to do so to consider the findings and implement changes recommended for improving both collaborative processes and youths' experiences within youth services in New Zealand.

\section{A Note about the Voice of this Text}

With the research aspect of this thesis focussing on empirical data from youth to enable a phenomenological study to be carried out, the rational for the study is also explained empirically by me as the principal author. Within the introductory and background chapters of the study certain examples and experiences will be shared in first person to illustrate the need for this study to be carried out in Aotearoa, New Zealand. Reasoning for this approach is two-fold: first, research relating to collaborative processes within youth work in New Zealand is limited in academic literature, and; second, there is a gap in empirical data providing first hand experiences of youth workers, particularly in New Zealand but also across the world.

With the research section of this thesis focussing on youth perspectives, the findings chapter will represent the voice of youth from across New Zealand sharing their experiences with youth services. Direct quotes will be highlighted with quotation marks, and/or written in italics. For confidentiality reasons, youth's names have been changed and programmes they are involved in will not be mentioned. The discussion chapter will bring together the empirical data from both myself and the youth, along with literature discussed in chapter three.

\section{Personal Background}

My ability to provide empirical data in the rationalisation of this study comes from first-hand experiences as an employee of the New Zealand Police for just under four and a half years. My time included three years working in the watch house where I was privy to the 
obstacles and frustrations colleagues were facing when working with youth, to then becoming a Youth Worker myself in a Youth Development Programme for an additional sixteen months. Initially thinking that I wanted to become a sworn officer and work in youth aid it was not long before I saw how bound Police Officers are by legislation and the focus on the crime rather than the young person. With a more preventive and positive outlook youth development became quickly more appealing as a career path and I was ecstatic when a position became available and I was finally qualified to fill it. Based in Auckland, the programme worked with youth between the ages of eleven and eighteen years old who had been referred either by Police Youth Aid or school staff due to their involvement in criminal or other anti-social behaviours that deemed them "at-risk". I was responsible for the twenty to thirty newest and youngest members of the programme. They came from six different intermediate schools within the stations boundaries and while a handful had previous Police involvement most had not, but rather struggled with school and came from homes where criminal activity, poverty, and/or drug and alcohol abuse were factors. The job was both rewarding and frustrating. Generally the youth were very special, with great potential, but helping them to realise that potential and enlisting others to help proved very difficult. While thoughts shared in the rationalisation are my own, discussions with colleagues and other networks are evidence to me that I am not alone in my experiences and concerns. 


\section{Chapter 2 Background to the Study}

\section{Purpose}

The purpose of this study is to explore youth's perspectives on whether and how collaboration is working for youth development in New Zealand. The study will examine youth's experiences of collaboration within youth intervention and prevention programmes and how collaboration may be improved to better focus initiatives to the needs of young people.

Further, the purpose of this study is to highlight the need for the youth voice to be heard in both policy making and evaluation processes relating to youth development. It is my hope that this study will open up an avenue for change and improvement that may be adopted both by current and future initiatives, policy making and practice for youth development.

\section{Rationale}

Youth in New Zealand hold a regular spot in the national news headlines due to issues such as binge drinking, youth gangs, underage prostitution, truancy, boy racers, and school rugby brawls. Media headlines are further supported by disturbing reports on statistics that show a rise in violent crimes and other anti-social behaviours among youth (Ministry of Justice, 2010). With the aim of addressing these concerns, youth programmes are increasingly being established across the country. The New Zealand Government is regularly discussing new laws and policy relating to issues such as binge drinking and boy-racers, and, there is an expanding number of both governmental and non-governmental resources available both online and within communities, including policing initiatives, Youth Week, the Ministry of Youth Development Website, local youth and community groups, and parenting programmes (Office of the Commissioner, 2005; Ministry of Social Development, 2006; Gluckman, 2010; National Youth Workers Network Aotearoa Inc., 2010; New Zealand 
Aotearoa Adolescent Health and Development; 2010). Such efforts seem to be a positive move in the right direction of supporting young people. A report on Police apprehensions for non-traffic offences between 1995 and 2008 shows that offending by 10 -16 year olds peaked in 2000 to make up $22.2 \%$ of the total apprehensions, and have since steadily decreased to be the lowest in 2008 making up 17.1\% of the total (Ministry of Justice, 2010a). However, while crimes such as theft and burglary have significantly decreased, violent offending is on a steady increase with a $13 \%$ increase of youth apprehensions in 2008 from the previous three years average (Ministry of Justice, 2010a). Violent crimes include acts such as grievous assault, minor assault, threats and intimidation, robbery, and homicide.

There are a number of governmental and non-governmental organisations across new Zealand that work with youth labelled 'at risk' due to criminal involvement or other factors. Some examples are the BreakThru Project, which works with gang involved youth in Counties-Manakau; Strengthening Families; The Pulse, a youth one stop shop in Whangarei, and; Youth and Cultural Development (YCD) in Christchurch (Ministry of Social Development, 2006). With a vested interest in reducing youth crime the New Zealand Police also have Youth Development Programmes (YDP) which are primarily aimed at youth who have either committed crimes or show potential of doing so. Police YDPs vary in their makeup across the country. Many are supported by a local trust and have a mixture of trust and Police employees. Some YDPs are linked in with a larger youth service set-up, such as The Pulse. These are generally made up of a manager and a group of youth workers and some may also include an administrative worker. Like most youth development services, the purpose of Police YDPs is to work with youth at-risk to help steer behaviours and life outcomes towards a positive future. With a growing understanding that for most repeat youth offenders there are a number of underlying influences and so simply enforcing the law is not adequate for curbing behaviours, the Police and other projects introduced above are striving to take a more holistic approach towards helping clients. 
An example of organisations working towards a more holistic approach can be seen in 'The Action Plan' section of The New Zealand Police National Youth Policing Plan 2005 2006, Objective 1.1, which reads: "To enhance and maintain effective working relationships with partner agencies, local authorities, community and youth organisations". It is further explained that this requires, "gaining support from and working alongside other government and national or local voluntary agencies to deliver high quality service to youth and their families". Two key actions are highlighted for achieving this objective. The first is “improving co-operative arrangements with other organisations which enables focussed multi-agency work against youth crime issues". The second is, "continued strengthening of inter-agency relationships through participation in community Youth Projects". Finally, amongst the key points to achieving these actions are, "Effective Police collaboration with stakeholders before commencement of policing campaigns dealing with youth issues", and "evaluated projects jointly managed by government and non-government agencies, which achieve desired outcomes" (Office of the Commissioner, 2005, p.29).

The need for a more holistic approach to youth services comes with the growing understanding that human behaviour is influenced by an array of contexts. There is an African proverb which states that it takes a village to raise a child. In New Zealand there is a whakatauki (Maori proverb) that reads "Ehara taku toa i te toa takitahi engari he toa takitini" which translates, "My strength is not that of the individual but that of the multitudes" (New Zealand Aotearoa Adolescent Health and Development, 2010). In the academic field, this concept is addressed in greater depth by social-ecologist Bronfenbrenner (1979, 1986, 1995 cited in Santrock 1999) who explains that people are connected to a myriad of networks that influence development. Networks for a young person might include family, peers, and school. A New Zealand-grown-model of holistic well-being that might help professionals who work with youth appreciate the various influences in a young person's life is Durie's (1994) model of Whare Tapa Wha. This model suggests that there are four areas in a person's life which are 
key to ensuring holistic well-being: Taha Tinana - physical; Taha Hinengaro - Intellectual and emotional; Taha Wairua - Spiritual; Taha Whanau - Family and social relationships. Durie's (1994) model extends the consideration of networks to include health practitioners, sports, church or other religious groups, and culture. For youth involved in programmes such as Police YDPs other networks might include Police, CYFS, and other support agencies.

Collaboration was one of the aspects raised in the National Youth Policing Plan for ensuring improved outcomes to youth intervention efforts and is further being increasingly called for across the board for youth and family services in New Zealand (Evaluation Unit of the Ministry of Social Policy, 2001; Christchurch Social Policy Interagency Network, 2003; Office of the Commissioner, 2005; Atkinson, 2006; Centre for Social Research and Evaluation, 2008). With a growing acceptance of the need to take a more holistic approach in working with youth, collaboration has been increasingly discussed as a means to achieving the ideal since the late 1980s (White \& Wehlage, 1995; Okamoto, 2001; Spergel, 2005; Wyles, 2007; Beadle, 2009). Collaboration is the concept of coming together for a joint project. With the young person being the 'joint project', and considering all that has come together to make this young person who they are, to work collaboratively is to accept that alone a single case-worker may not have all the expertise and resources to successfully get the young person on track (Okamoto, 2001; Head, 2003; Walker, 2007). As will be discussed further in Chapter 3, there are a number of levels of collaboration. For the purpose of working with individual youth to improve life outcomes, case-level collaboration is most appropriate. Case-level collaboration works on the basis that the young person's needs are the central priority and that all that have the resources and expertise to provide help will come together under a collaborative framework to ensure those needs are met (Okamoto, 2001).

While there is no specification that Police YDPs take on the case-level collaborative approach, many of the elements outlined in the National Youth Policing Plan (Office of the Commissioner, 2005) above point to the need for taking it on. Having been a Police YDP 
youth worker myself, the need for a collaborative approach was particularly apparent to me when reflecting upon how the many interventions from differing agencies might impact on the young person. As youth involved in YDPs tend to have a number of needs to be addressed, they also tend to have numerous professionals working with them, both within the school and other agencies such as the Police, CYF and healthcare workers. Something that raised concern for me was that upon visiting youth to address issues that had arisen over recent weeks or to work on goals for development, I was often met with a frustrated or overwhelmed young person that was being dealt with by various people at both professional and personal levels. At such times, the majority of our visit was spent discussing other interventions or disciplinary actions that had been carried out by another and deconstructing the situation to first settle the young person leaving little time to make headway elsewhere.

While collaborating expertise and resources together means agencies involved with youth should be able to achieve results more effectively, more importantly it can minimise conflicting and overwhelming interventions for the young person. The latter is fundamentally important for youth who are already struggling within the system, be it education or criminal, as their experiences often leave them fragile and untrusting. Returning to my own experiences outlined in the previous paragraph, there were times that a young person was so frustrated with the various intervening adults (parents, school \& youth worker/s) that they would put up barriers such as disinterest or silence, communicating that they had given up altogether and did not want anyone's help. At times this could take weeks to work through before the young person was willing to re-commit to the programme. One youth gave up on the programme all together due to conflict within himself regarding too many youth workers being involved. To have to deal with a number of different professionals, meet a number of differing expectations, some of which may be overlapping or contradicting, and possibly being told you are not meeting those expectations a number of different times a week would wear anyone down, let alone a youth dealing with both puberty and well-being concerns. 
My experience as a youth worker was that while collaboration was often discussed as the ideal, it proved difficult with obstacles such as time, lack of effective training for carrying out such meetings, differing agency agenda's (due to funding and policy), and engaging families. Further findings in the literature reveal that my own concerns are common to experiences across the sector internationally (White \& Wehlage, 1995; Okamoto, 2001; Wyles, 2007; Beadle, 2009). In acknowledging the already heavy workloads and lack of resources of Police, schools and social services, challenges to collaboration within YDPs can be appreciated.

Despite the challenges that face collaboration in the social sector, a handful of studies and evaluations carried out in recent years within New Zealand and Australia give evidence that it is possible to achieve (Atkinson, 2006; Wyles, 2007; Beadle, 2009; Strengthening Families, 2010). While examples in the literature regarding successful outcomes for youth intervention programmes through collaborative efforts are limited, there is even less relating to the experiences of youth themselves. Through a better understanding of the youth perspective, the application and successes of the collaborative approach for youth services in New Zealand can be gauged.

\section{Aim of the Study}

It is intended that this study will add to understandings of collaboration for youth development in New Zealand, through the voice of youth. This will be achieved by interviewing youth who have had varying levels of involvement with one youth service or another using an Appreciative Inquiry framework. I am particularly interested in ensuring that the experiences of young people are heard due to the lack of current literature reporting youth experiences in their voice. As youth participate in the interview, they will be given the opportunity to consider their ideal collaborative team and approach. It is intended that this 
will empower them to not only appreciate the people and resources available to them but to consider taking ownership of accessing them.

Each youth will be representing their own experience only. While this may limit the extent to which this study can be generalised it will still enrich the current knowledge base and allow practitioners and policy makers alike to more fully appreciate the many facets of collaboration that are in need of addressing. The aim of this study is to provide a strengthsbased exploration of collaboration through the voice of New Zealand youth.

\section{Research Questions}

\section{Main Research Question}

a. What are New Zealand's youth's experiences of collaboration when involved with youth development services?

\section{Sub-Research Questions}

1. What level of involvement has the young person had with youth development services in New Zealand?

2. To what extent has the young person experienced collaborative processes through their involvement with youth development services in New Zealand? What was their experience?

3. If the youth could choose a team of people to work with them through their needs, who would they select? And why?

\section{Significance of the Study}

The findings of this study will be used to examine and help improve collaborative processes for youth work. This includes taking a deeper look at what is meant by collaboration in the literature and to those who collaboration is aimed at - the youth. The study is intended to provide insight that will influence future policy-making in youth, community and policing sectors to ensure that collaborative practices are more youth centred. 
This will be achieved through the unique approach of a youth perspective that has in the past been overlooked, as highlighted by a gap in the literature to be discussed in chapter three.

Of further significance is that, in my review of academic research in New Zealand, the Appreciative Inquiry framework does not seem to have been used previously in this type of study. This study will therefore also introduce the possibilities of the framework's suitability for addressing concepts of collaboration and youth/client voice within youth and social development sectors in New Zealand.

With the use of the Appreciative Inquiry framework, it is further intended that youth will be empowered through being given a voice in sharing their perspective. Evidence of the empowering effect of youth voice is discussed later in the thesis. Additionally, it is hoped that an immediate benefit of this study will result in youth considering who to turn to and what services might be available for them for further assistance in the future.

\section{Conceptual Framework}

The intention of phenomenology is to understand how a person or multiple people experience a phenomenon. A phenomenon is an observable occurrence, in this case collaborative practice within youth development services. With the intent of understanding the youth perspective on collaboration in New Zealand, a phenomenological qualitative research approach seems most appropriate, as it allows for empirical data to be collected from the young persons' themselves. Phenomenology will allow me to understand collaboration from a youth perspective which is likely very different from that of my own. To fully appreciate the lived experiences of the participating youth, in-depth interviews will be carried out utilizing key principles of the Appreciative Inquiry framework.

A framework influenced by and created to challenge aspects of action research is Appreciative Inquiry. With action research requiring participants within a team or community to come together to address problems through action, AI uses socio-rationalist theory which 
describes reality as something that is continuously evolving rather than something stable and enduring that if not working can be simply fixed or solved (Bushe \& Coetzer, 1995). Appreciating the constant changes within society and influences affecting today's youth support this notion of socio-rationalism. Often explained comparatively with action research, the key difference is that instead of being 'problem' based, AI celebrates what is and explores what can be. This is called positive presumption (Cooperrider \& Whitney, 2005). Another outstanding aspect of $\mathrm{AI}$ is that when implemented properly it can bring about change that is influenced by both professionals on management and frontline levels and those most affected by a programme, the cliental.

Over time two sets of principles for Appreciative Inquiry have emerged (Bushe, 2005). The first set of principles are from Cooperrider and Srivasta's (1987) initial conception of AI. In their call for a "refiguration of action-research" Cooperrider and Srivasta describe four principles that are imperative to AI being a successful means for change; it needs to:

1. Begin with appreciation

2. Be applicable

3. Be provocative

4. Be collaborative

To begin with appreciation is to consider what is working within the organisation, appreciating the organisation's strengths. This is a contrasting approach to the conventional methods of looking for problems to be solved. The AI stance against problem-solving is discussed further in this section. Secondly, the outcomes of an Appreciative Inquiry need to be applicable if change is going to be long-lasting. To be applicable it must be actionable. The notion of being provocative requires AI participants to change their thinking as change results in change. If different outcomes are desired, different approaches must be attempted. 
Finally, as organisational change is most effectively implemented when all are on board AI requires a collaborative approach that allows all involved in the organisation to share their stories and participate in the process of development.

The second set of principles that have been introduced is really a deeper extension of the initial set but with a more theoretical framework that has been tried over time. In their overview of Appreciative Inquiry from conception to its current state, Cooperrider and Whitney (2005) address five basic principles that they feel have been key to driving the framework for change, which are:

1. The Constructionist Principle

2. The Principle of Simultaneity

3. The Poetic Principle

4. The Anticipatory Principle

5. The Positive Principle

The Constructionist Principle explains that AI is a communal process for constructing new knowledge and understandings to allow for future change and development. They link this principle with Gergen's $(1982,1994)$ concepts of 'generative theory' and 'communicamus ergo sum'. Generative theory calls for a move away from the traditional methods of making assumptions based on the past towards experimenting with possibilities of the future through a change of language and outlook (Gergen, 2009). Communicamus ergo sum which translates to 'we communicate, therefore I am!' Gergen (2009) uses a socialconstructivist explanation for describing how people's convictions come through relationships and interdependency. The Constructionist Principle therefore calls for relational experiences of sharing, questioning and innovation so that a generative capacity of knowledge may be developed (Cooperrider \& Whitney, 2005).

The Principle of Simultaneity carries along from the above as it recognises the interdependence of inquiry and change. That is, as questions are raised, change is already in 
its beginning stages for it is the findings or discoveries from such questions that motivate the implementation of change (Cooperrider \& Whitney, 2005). While Bushe (2005) explains how this principle highlights the fatefulness of questions this should not be misunderstood for cautioning against only asking certain types of questions. Cooperrider \& Whitney reinforce that even the simplest or seemingly non-challenging questions can arouse change simply through reasoning of our social make-up. In regards to caution, they merely advise that instead of worrying about whether a question is worthwhile, consider what impact the question has on the inquiry. Even a humorous question can have the impact of lifting spirits and is therefore a positive contribution.

The Poetic Principle is explained by Cooperrider and Whitney Whitney (2005) through the metaphor that human organisations are like a book to be read as opposed to a machine that runs to prescription day in and day out. The stories of human organisations are constantly being written by numerous authors at a time and each story is made up of different experiences and perspectives unique to another. AI encourages these stories to be told and explored. Gergen (2009) explains how changing language and outlooks on entering the inquiry phase ensures a form of poetic activism as risks are taken and alternative possibilities are opened up. An example of altering language and outlooks that Gergen uses is in the idea of addressing street crime. He questions what possibilities might be opened up if, instead of approaching the concern conventionally through research and policy implementation, outlooks surrounding street crime were reconsidered. He asks, "what if street crime was viewed as a means towards enhancing self-esteem?" (Gergen, 2009, p. 82). Essentially, The Poetic Principle requires thinking outside the box or getting creative in the story-telling process, stop following the same predictable plot.

Just as one might predict the outcome of a romantic comedy that is following a commonly used storyline, The Anticipatory Principle (Cooperrider \& Whitney, 2005) depicts the idea that the future of an organisation can be seen through its current behaviour. Bushe 
(2005) describes the principle clearly as he states that "what we do today is guided by our image of the future" (Bushe, 2005, p. 6). So, if an organisation is full of people who have a united vision of a positive future this should be recognised by an outsider who comes into the workplace by what is seen in the hallways, the language that is being used, the positive actions that are playing out.

The Anticipatory Principle and The Positive Principle are closely linked. Cooperrider \& Whitney (2005) illustrate it best through their own experience: "building and sustaining momentum for change requires large amounts of positive affect and social bonding - things like hope, excitement, inspiration, caring, camaraderie, sense of urgent purpose, and sheer joy in creating something meaningful together" (p. 17). With their explanation that a system will grow in the direction of the questions it asks, it can be seen that a positive outlook of inquiry will generate positive outcomes as actions are guided by the anticipation of the organisation as a whole. Here can be seen the coming together of the two concepts, appreciation and inquiry.

With the desired outcome of research being to discover new avenues for organisational growth and development, a process of questioning must be followed to achieve this. Cooperrider \& Whitney (2005) explain this process as an art form, that is, to be able to question in such a way that strengthens systems instead of breaking them down. Such questions should develop an inquiry into past and present organisational capacities such as "achievements, assets, unexplored potentials, innovations, strengths, elevated thoughts, opportunities, benchmarks, high point moments, lived values, traditions, strategic competencies, stories, expressions of wisdom, insights into the deeper corporate spirit or soul-- and visions of valued and possible futures" (Cooperrider \& Whitney, 2005). They explain that making such positive inquiries creates a 'positive change core' that opens minds up to not only recognising what has and is being achieved but in addition the organisations future potential. They further emphasize that in using the concept of a positive change core, 
an organisation will be most successful in achieving sustainable and motivational change if they get all involved in its conception.

In academic research terms the notions above have been outlined as allowing for grounded theory research to be carried out as empirical data is first obtained from stakeholding participants before making a qualitative analysis (Glaser \& Strauss, 1967; Strauss \& Corbin, 1998). In essence, proper use of AI can bring about change that is influenced by both professionals on management and frontline levels and those most affected by a programme, the clientele.

With the success stories of applied AI in youth development programmes, community empowerment projects, community health initiatives and race relations, as found in Hammond and Royal (2001) it seems like potentially a perfect fit for research on youth services in New Zealand. AI supports a number of the core values outlined in the code of ethics for youth workers in Aotearoa New Zealand (National Youth Workers Network Aotearoa Inc., 2008). Values such as using strengths-based approaches, acknowledging the cultural connections of a young person, nurturing respect, valuing relationships, and promoting inclusion are all accessible through appreciative inquiry. While AI ideally works in group discussion settings, there have been times when the initial stages of the process require individual interviews be carried out first to establish where participants are at and what it is the organisation really wants to address (Cooperrider \& Whitney, 2005). This research may be considered as the initial step, establishing what Cooperrider \& Whitney (2005) have coined 'the unconditional positive question', to a fuller inquiry into collaboration for youth development to be carried out across youth services in New Zealand under the AI framework. 


\section{Underlying Assumptions}

Whilst there seems to be a lack of literature regarding collaboration in front-line community and youth development sectors in New Zealand, the many calls for its improved implementation are evidence that there is an awareness of the benefits collaboration has to offer and that it is being implemented to some degree. It is assumed that this awareness and some amount of experience with collaboration will enable youth to share some degree of experience with collaboration, even if at first the actual term is foreign to them.

\section{Limitations}

One of the limitations in using the AI framework is that there is an assumption that participants will be willing to share their stories, though some may not. Good facilitation of interviews is intended to reassure youth that their opinions and experiences are not only valued and interesting but crucial to the improvement of services for New Zealand youth in the future.

A final limitation of this framework is that it will not allow for representation of all youth across New Zealand. Despite this, the perspectives from a small sample of youth from differing programmes and areas of New Zealand should provide sufficient perspective to gauge a degree of understanding of the youth perspective.

\section{Definitions}

Collaboration: For the purpose of this thesis, collaboration means the extent to which professionals, families and the young person work with one another to plan and carry out a youth-centred process of intervention and prevention for positive change and growth. Youth development programme: An umbrella term for any youth programme or service working with youth at risk for a period of time. 
'Youth at Risk': A term used by government and non-government agencies to describe young persons who have either committed criminal acts or show high potential of doing so.

Youth and Young Persons: New Zealand policy tends to define anyone under the age of 14 years as a child, and 14-16 year olds as young persons. The varying youth development programmes mentioned within this study work closely with intermediate and college aged youth which include young persons aged 10 and 18 year olds. For the purpose of this study, 'youth' and 'young persons' are to be understood as 10 to 18 year olds.

\section{A Snapshot of Youth in Aotearoa New Zealand}

In 2009, young persons in New Zealand aged 0-24 years old made up 35\% of the population which then stood at approximately 4.35 million. Around $86 \%$ of the total population lives in urban areas. In 2006, $72 \%$ of youth identified themselves as being of part or full European/New Zealand descent, $24 \%$ of Maori descent, 12\% Pacific Island, 10\% Asian and $1.2 \%$ other. Eighteen percent of young people identified with belonging to two or more ethnic groups and this number is expected to increase as ethnic diversity and interethnic marriages and partnerships become increasingly common (Ministry of Social Development, 2011).

While the percentage of school leavers leaving with higher-level qualifications has consistently increased from under $20 \%$ in 1986 to $71 \%$ in 2008 the disproportionate gap between sexes and ethnic groups continues to exist. In 2008 66\% of males left school with

National Certificate of Educational Achievement (NCEA) level two or above, while a significantly higher $75.8 \%$ of females achieved the same. A breakdown of ethnic groups reaching this level of achievement outlines that Asians were most successful with $85.8 \%$, followed by Europeans at $75.2 \%$, Others at $70.3 \%$, Pacific Islanders at $62.9 \%$ and Maori at 50.4\%. (Ministry of Social Development, 2011) 
Between 2007 and 2009 the unemployment rate for 15-24 year olds was four times higher than that of 25-64 year olds. This is a significant increase from the previous twenty years when the difference has been two to three times higher. Amongst all age groups Maori have the lowest income levels, followed by Pacific islanders, then others. Europeans had the highest. (Ministry of Social Development, 2011)

With 15.3 suicide deaths per 100,000 (94 total) 15-24 year olds in 2007 youth suicide rates in New Zealand are second highest in the world. The suicide death rate for Maori youth (28.1 per 100,000$)$ is more than double that of non-Maori youth $(12.3$ per 100,000$)$. Suicide is more common in deprived neighbourhoods. (Ministry of Social Development, 2011)

Potentially hazardous drinking (PHD) as defined by the Alcohol Use Disorders Identification Test (AUDIT) is highest amongst 15-24 year olds with the proportion of drinkers showing PHD patterns standing at 41.1\%. The next highest age group are 25-34 year olds with $27.1 \%$ of drinkers showing PHD patterns. Male youth drinking patterns are shown to be more hazardous than female youth and Maori and Pacific Island patterns more hazardous than European and Asian. (Ministry of Social Development, 2011).

Young persons under the age of 21 made up $40.5 \%$ of criminal apprehensions between 2009 and 2010. With a decrease in property offences which comprise the largest portion of youth apprehension the youth crime rate overall is decreasing. However, youth apprehensions for violent offences are increasing with the 2008 rate of 198 violent crimes sitting 13\% above the average for the period between 1992 and 2008. Young persons aged from 0-20 years old have the highest rate of robbery, unlawful entry and property offences amongst all age groups and they make up $22 \%$ of homicide related apprehensions. Finally, Maori children (10-13 years old) were apprehended five times more than their Pacific and European counterparts, and Maori youth (14-16 years old) three times more. (Ministry of Justice, 2010). 
The above statistics are evidence that media hype is not solely to blame for poor perceptions surrounding New Zealand youth today, the issues are real and numerous. Efforts are being made for change and much of it is likely making a difference in individual lives. Unfortunately, however, on a grand scale it would seem that current efforts are not enough. The following chapter reviews literature surrounding youth and collaboration as it pertains to youth intervention and development. 


\section{Chapter 3 Literature Review}

In this chapter I focus on literature relating to youth and collaboration. In the first section I look at concepts and definitions of youth both as it relates to policy and as a developmental stage in the human life-span. The second section is an in-depth exploration of collaboration. I first discuss the general concept of collaboration followed by an examination of its current definitions and features. I then highlight examples of collaboration in action within social services in New Zealand and youth services internationally which I then use to outline factors for success and challenges to overcome. Finally, I explore the matter of who should be contributing to collaborative processes within youth services.

\section{Youth}

In New Zealand, young men and women aged between 12 and 24 years old are considered 'youth' by the Ministry of Youth Development (Ministry of Youth Development, 2005). Such a broad inclusion can be confusing both for appreciating what it means to be a youth as well as how and why different laws and policies effect youth of different ages, especially as there is little consistency across government agencies. Such inconsistencies can be seen in the snap-shot statistics discussed in the previous chapter where there is no set age bracket for statistical purposes. While the Ministry of Justice (2010) defines children as those aged 10-13 years old and youth as 14-16 years old, the Ministry of Social Development (2011) has used age brackets of 15-24 year olds in some areas of their report and 0-17 year olds in others. Beals (2006) describes further inconsistencies of youth definitions in law and policy as she highlights how a 16 year old can legally choose to have sexual relations, get married, and drive a car but still has to bring a note to school from the parents when late or absent. 
Within academic literature, the term 'youth' is often discussed hand in hand with adolescence (Santrock, 1999; Bird \& Drewery, 2000; Vasudevan \& Campano, 2009). Bird \& Drewery (2000) explain that differentiating the two terms is becoming difficult as definitions are vague. Both terms relate to the stage that comes after childhood and before adulthood which begins around the time that rapid physical changes are happening with the onset of puberty (Santrock, 1999). Beals differentiates between the terms as she explains that while 'adolescence' evolves from psychological and biological contexts, 'youth' is a social construct that is dependent on contexts for finer clarification. This explanation substantiates the suitability of the use of the term 'youth' when discussing this age group in the context of social development.

In traditional theories of human development, youth or adolescence is noted as an integral stage in a person's life for the production of personality and understanding by theorists such as psychoanalysts Freud (1917, cited in Santrock, 1999), Freud (1966) and Erikson (1963). Included to some degree in each of these theorists' works is the idea that inner conflict is integral to a person's development and that only by overcoming or repressing it can one progress.

As the founder of psychoanalytic theory Sigmund Freud (1917, cited in Santrock, 1999) introduces the concept of 'psychosexual development', constructed from the belief that personality is developed through conflict between sources of pleasure in the early stages of life. These sources are described as the 'oral', 'anal', 'phallic', 'latency', and 'genital' stages of development. The 'genital stage' being the fifth and final stage begins with puberty. He explains this as a stage of sexual reawakening after having repressed such feelings in the earlier phallic and latency stages. Along with this reawakening comes the re-emergence of unresolved conflict with parents which only when addressed will allow the person to be able to develop mature loving relationships and the independence to function as an adult. 
Anna Freud (1966) extends her father's work to explain how the psychosexual stages of development influence the internal emotional upheaval that youth experience in the adolescent years. She tells how the psychological defences developed to supress urges in early childhood are insufficient for dealing with the increased urges that puberty brings, resulting in an upset of the psychic balance (Coleman ,1978).

Erikson (1963) appreciates the Freuds' contributions but ascertains that as humans continue to develop throughout the life span more stages of development are required than those which focus solely on the early years. In a revision of Freud's work, Erikson established the eight psychosocial stages of development which focus more on the social influences in a person's life than on the sexual. In line with Freud's (1917) model each stage relates to an age bracket and includes some form of developmental conflict. For example, the first stage a human faces is that of 'trust versus mistrust' when as a baby one requires safety and comfort which if not felt can lead to fear and apprehension about the future. Erikson's fifth stage relates to adolescence, which he approximates to be between the age of 10 and $20 \mathrm{yrs}$ old. This stage is called 'identity versus role confusion' and relates to a person discovering who they are, what they are about, and where they are going (Erikson, 1995; Santrock, 1999).

If the above theories are used to understand youth a picture of tension, frustration and confusion begins to form. This is essentially what happened through a good part of the twentieth century when much of the literature described this stage of a person's life as troublesome with adjectives such as 'raging', 'boisterous', and 'unruly' attached to it (Bandura, 1964; Monge, 1973; Coleman; 1978; Bird \& Drewery, 2000; Beals, 2006; Vasudevan \& Campano, 2009). Bird \& Drewery further explain that while in recent decades there has been a growing consensus in the academic world that such negative constructions are seen as paralytic, instead of analysing and breaking down such constructs they continue to be reinforced. There are, however, some studies that do break down such constructs forcing 
the reader to consider youth in a different light (Bandura, 1964; Monge, 1973; Coleman; 1978).

In articles discussing whether adolescence really is the stormy season in a person's life that it is made out to be, Bandura (1964) and Coleman (1978) highlight a number of factors that refute the idea. Whilst Freud (1917) claims that parental resent and conflict needs to be addressed at this stage in life Bandura on the other hand discusses interviews with teenage boys who describe their parents as supportive and unrestricting. Coleman also finds little evidence of communication difficulties or withdrawal from parents. Instead, he describes how youth tend to attach themselves to peer-groups that reinforce the values of their parents. Coleman explains that most teen-parent conflicts revolve around mundane issues such as tidiness and punctuality. Furthermore, serious non-conforming behaviour that may exist amongst some teenagers is not necessarily due to onset at puberty but becomes more obvious at this stage because the young person is bigger and more powerful making behaviours harder for parents to supress. In fact, both Coleman and Bandura point out, along with Monge (1973), that puberty may have much less to answer for than it is given credit for with studies finding that human sexual behaviour is influenced more by social conditioning than it is by physical urges.

With respect to Erikson's (1963) youth identity crisis Coleman argues that while young people are certainly likely to be concerned with decisions about their future and where they fit in the world there is little evidence of this reaching crisis level for the vast majority. He further indicates that the greatest uncertainty about self has been found to happen between the ages of eight and twelve years old, rather than in the teens.

In conclusion to his work, Coleman (1978) resolves that while evidence may highlight flaws in the theories that describe youth as a stormy and unsettling time, he does not feel that empirical findings of it being a harmonious time are completely correct either. He explains that flaws in empirical findings may be due to poor interviewing skills and reserved 
interviewees that might result in biased findings due to youth not being completely honest and open in their answers. He justifies this concern by explaining a large scale study which identified that throughout the adolescent years individuals do go through challenging experiences such as conflict with parents, fear of fitting in and anxiety over romantic relationships, they just do not generally result in crisis. Instead, the result led him to propose his 'focal theory of adolescent development' which explains how at different ages different patterns of relationship challenges come into focus more prominently than others. For most the challenges come one at a time and none are seen to be the precursor to the next. For the minority however, multiple challenges may arise and it is these cases that are more likely to result in crisis.

Along with highlighting the earlier contradictions to psychoanalytic theory, both Coleman (1978) and Bandura (1964) consider possible causes of such differing views. Of In particular, Freud (1917) and Erikson (1963) gained their understandings through occupational experiences in mental health and so their sample population of adolescents would not fairly represent adolescents in general. Coleman and Bandura also highlight undue prominence of negative adolescent behaviour in the public eye, such as mass media, which can then create a self-fulfilling prophecy effect as society learns to expect teenagers to display rebellious behaviour.

Bird \& Drewery (2000) also highlight the influence of media as playing a key role in reinforcing negative constructions of youth as they introduce what Cohen (1972) terms 'moral panic'. Moral panic can be understood as the over-generalisation and attention on a current affair or statistic of negative nature. Fattore, Mason and Watson (2009) address the concern from a different angle stating that literature too often discusses what we do not want for our children and young people instead of what we do. They explain that the impact of this is that policies and services focus too much on responding to concerns and too little on promoting positive standards (Fattore, Mason, \& Watson, 2009). 
There is a growing desire amongst academics to move away from such negative focuses on youth (Bird \& Drewery, 2000; Beals, 2006; Fattore et al., 2009; Vasudevan \& Campano, 2009). Instead, there has been a move in the direction of understanding youth as a sociocultural concept, also known as social construction or contextual understandings (Bird \& Drewery, 2000; Beals, 2006; Vasudevan \& Campano, 2009). Beals explains contextual understandings as allowing for the term youth to be used flexibly within varying contexts. This comes from the notion that while the word 'adolescence' carries more of a scientific definition of development, the word 'youth' is a sociological construction that is situation dependant. Bird \& Drewery explain the social construction of youth as a result of Western industrialisation organising the human lifespan by creating "economic roles and social positioning" (p.140). Beals explains that using this contextual understanding is most useful to youth studies research as it "allow[s] the analyst to explore youth and the knowledge that constructs youth in context” (Beals, 2006, p.39).

The focus of Beals' (2006) work is on definitions and constructions of youth deviance as she explains concepts of 'normally-deviant youth' and 'abnormally-deviant youth'. Where normal deviance can be explained as 'risk-taking' and a 'passing phase', a young person with abnormal deviance is more commonly described as a 'youth-at-risk'. Resnick \& Burt (1996) explain the term 'youth-at-risk' as a way of differentiating those youth who simply experiment with negative behaviours but come out the other end as productive, participatory citizens in society and those who fall victim to the negative behaviours they experiment with. Beals explains that a key difference between the two is that the abnormally deviant person shows behaviour concerns at a much earlier age and in many cases there are family related issues. Where 'normally-deviant youth' relates to a phase of development, 'abnormallydeviant youth' is seen to be a lifelong concern (Beals, 2006).

Resnick \& Burt (1996) discuss the notion of 'risk' as being an uncertain predictor that is, youth considered at-risk are believed to have a greater chance of on-going problematic 
behaviour but are in no means destined to. They further explain that youth can be classified as high-risk and low-risk so as to determine the level of intervention required to assist them. Being at-risk, they explain, is not so much determined by the amount of risky behaviour a young person participates in, but instead the "risky situations or environments" they might live in (Resnick \& Burt, 1996, p.173). Such situations can include dangerous neighbourhoods, negative role models and inadequate housing. Resnick \& Burt acknowledge how the above information may be misinterpreted so as to conclude that all youth living at the lower end of the economic ladder are therefore considered 'at-risk'. To the contrary they explain that risk-factors are displayed fairly amongst various communities and economic backgrounds as are resilience factors. They carry on to say that a better determinant of riskfactors can be understood through Bronfenbrenner's (1979) ecological model of development. That is, that there are a number of contexts which influence a young person's development such as family, community and other institutions and that while a lack of resources, or money, amongst such contexts can be a contributing factor to vulnerability so can high-stress, dysfunctional relationships and lack of support - all of which are not necessarily economically determined. Using the ecological model, Resnick \& Burt go on to explain risk markers and problem behaviours that may be influenced by the aforementioned contextual factors. Two examples they give of risk markers are poor school performance and foster care. Some examples of problem behaviours include substance abuse, early sexual activity, running away from home and criminal activity. They explain that the ecological model of understanding risk further highlights the need to address youth-at-risk, or youth who have displayed problematic behaviours, taking the various contexts into consideration. They argue that too often, interventions focus on the displayed behaviour only and not on the surrounding contexts. To overcome this need they explain that a multi-disciplinary or integrated service approach is necessary to ensure that all bases are covered instead of filling one hole only to uncover another. 
The concept of integrated services has become increasingly popular with the growing consensus that human behaviour is influenced by an array of contexts and has prompted the call for more holistic approaches to youth and community services in the social sector (Ministry of Social Development, 1999; Walter \& Petr, 2000; Office of the Commissioner, 2005). Throughout the literature there are a variety of holistic approaches which can both supplement and overlap one another. Collaboration is a holistic approach that is often spoken of both within the literature and across government sectors (Okamoto, 2001; Atkinson, 2006; Maori Reference Group for the Taskforce for Action on Violence within Families, 2009). The term collaboration is used interchangeably with co-operation, co-ordination, networking and partnerships (Atkinson, 2006). Within this text I will make a clear definition between collaboration and some of the other aforementioned terms.

\section{Collaboration}

As Walter \& Petr (2000) explain, the concept of inter-agency collaboration has come hand in hand with the evolution of service integration initiatives. They explain inter-agency collaboration as a strategy for developing more comprehensive and efficient services for families and children with multiple needs to replace the disjointed services that have previously been available. Sanders \& Munford (2005) reinforce this need as they explain the significant risk that is placed on young people who are not always invited to speak for themselves when professionals come on board to work with them with limited information or partial knowledge.

Laursen (2000) and Flores (2007) explain the benefits of collaboration for service professionals. Attributing a lack of working together to professionals in high-stress education and social sectors becoming burnt out, they explain how the support that results from a collaborative effort will ensure greater staff retention, improved information sharing and colleague training, and a generally happier work environment. Such a concept might be more 
fully understood through Culturalism which explains that the society within which a person exists has a profound impact on that individual (Wearmouth, Glynn and Berryman, 2005). If a person is feeling well supported and resourced in their working environment, at both the immediate and broader levels, they are more likely to feel they belong, enjoy greater job satisfaction and therefore achieve greater outcomes for their clientele.

While the need for inter-agency collaboration is becoming increasingly prominent both within international literature and within reports and government plans relating to youth and social issues within New Zealand (White \& Wehlage, 1995; Christchurch Social Policy Interagency Network, 2003; Office of the Commissioner, 2005; Centre for Social Research and Evaluation, 2008), there is a lack of literature on actual experiences of and best practices for collaboration in the social sector. Beadle (2009) sums up this concern as she states that "while the need for holistic health and social practice is increasingly being articulated in Australia, the discussion is not always matched by improvements in service delivery"(Beadle, 2009).

\section{Definitions and Features of Collaboration}

Collaboration has been defined in many ways across the sectors. Having considered a number of works and definitions, Wood and Gray (1991) found that there were similarities in most but nothing comprehensive enough to cover the many facets of the phenomena. In response to this concern, they issued a definition of their own: "Collaboration occurs when a group of autonomous stakeholders of a problem domain engage in an interactive process, using shared rules, norms, and structures, to act or decide on issues relating to that domain." (Wood \& Gray, 1991, p. 146).

To expand on their definition, Wood \& Gray (1991) explain that stakeholders refer to a group of people with an interest in the domain. They note that these interests may be common or different to start with but are likely to be redefined through the collaborative 
process. Often professionals from differing agencies will come with different agendas and expectations of a meetings outcomes but it is hoped that the process of good collaboration will enable participants to build a shared goal that each can bring their expertise to the table for achieving. They further highlight that an 'interactive process' emphasises the expectation that all participants be actively involved and that ensuring there is a pre-determined set of rules, norms and structures that will govern their interactions is a must.

Head (2003) states that, "at the simplest level, collaboration comprises a range of closely related acts such as coordinating, consulting, communicating and cooperating" (2003, p.50). Similarly, Okamoto (2001) explains that for youth-serving agencies, co-operation and communication are essential elements to collaboration as they minimise over-lapping and ensure mutual understanding, shared goals and good integration.

Highlighting that the Latin roots of the word mean 'working together', Walter \& Petr (2000) explain that collaboration has been discussed as a structure of working together, a process of working together, an attitude of working together, or a relationship of both formal and informal components of working together. When considering each of these separate entities however one cannot fully appreciate the true concept of collaboration in its multifaceted fullness. To consider an attitude of working together without the other components is to simply co-operate. Again, a relationship of working together could simply be co-ordination. Vague explanations such as those stated above that might allow one to argue that collaboration is simply the 'hot word' currently being used in place of cooperation, co-ordination or networking and that it is just an old process with a new name. Knight, Knight, \& Teghe (2007) clarify some key points of collaboration as they explain how it differs from co-operation:

Whereas in cooperation there is a rather loose and less-binding relationship, collaboration refers to a durable and pervasive relationship in-which previously separated organisations are 
brought together with full commitment to a common mission. Such relationships require comprehensive planning, and welldefined communication channels operating at many levels. Risk is much greater than simple cooperation because each member of the collaboration contributes its own resources and reputation. (Knight, Knight, \& Teghe, 2007, p.51)

The first point that Knight et al. (2007) raise is that collaboration must entail both the working relationship and the common mission. For the purpose of fulfilling the mission there must be good planning and communication, which might translate as structures and attitudes. Finally, as each member contributes, they also take responsibility for outcomes. It could be said that in covering each of the above points a collaborative process that involves the relationship, structures, and attitudes that Walter \& Petr (2000) mentioned can now be seen. Furthermore, with the use of slightly different terms this explanation is basically in line with the definition of Wood \& Gray (1991).

The notion of an interactive process, as explained by Wood \& Gray (1991) stands out as an important aspect of collaboration. Okamoto (2001) explains that collaboration is a "communicative process" which involves information sharing, negotiation, planning, management and decision making. Head (2003) adds to this idea as he describes collaboration as an intermediary process where something must first happen to bring the group of individuals together to deal with it through their various means. In the case of youth development, this explains that there has to first be a youth in need of help before the collaborative process takes place. The process begins with the relationships being established through some form of networking. Structures and rules are then put into place in a cooperative attitude, which allows shared responsibility in taking action according to the resources that each member has to bring to the table.

Walker (2007) reinforces the aspect of shared power and responsibility as she describes it as being "central to the notion of collaboration" (p. 113). She further highlights 
that while good structures and working well together are important aspects of collaboration, they should not be mistaken for successful collaboration as this can only be measured through the outcomes of the process. In New Zealand, the 'Mosaics' document produced by the Ministry of Social Development (2003) reinforces this idea when it states that, "Collaboration cannot be an end in itself. It must deliver clear and measurable outcomes for individuals and communities, and create benefits for the people, agencies, and organisations involved" (p.5).

The 'Mosaics' document (Ministry of Social Development, 2003) explains that there are two levels or types of collaboration being focussed on through current government initiatives. At the strategic level is regional co-ordination which has the purpose of giving an overview of agencies and their activities within an area to allow for planning and aligning of resources amongst organisations. At the operational level is integrated service delivery which has the purpose of meeting the needs of smaller communities, client groups, families or individuals through an inter-agency approach. These two levels of collaboration are closely related as activities at one level may require initiatives to be carried out at the other. For example, a regional co-ordination project may call for involvement of integrated service delivery.

Okamoto (2001) also explains two different types of collaboration within the social sector, system-level and case-level. System-level collaboration is essentially what the Police have in operation within YDPs, professionals working together within the Police system. Police YDPs consist of police officers and non-sworn youth workers and are often supported by a trust for funding and other needs. It is intended that as Police and non-sworn youth workers bring their respective resources and networks together and are supported by a trust with a focus on local community interests the opportunity to provide a "holistic wrap-around service" to youth is enhanced (Office of the Commissioner, 2005). The community focus and support of a trust allows for YDPs to cater to local needs in a way that a Police only driven programme may not achieve. 
Case-level collaboration might be seen as the next step to system-level collaboration. It happens when YDP workers reach out to other agencies to access services they cannot provide, as in addiction or sexual health services. Okamoto (2001) explains that the key to case-level collaboration is that it focuses on implementing an intervention that meets the client's needs instead of trying to fit the client into the agencies' systems. The case-level collaboration that Okamoto describes can be achieved through what is commonly known as inter-agency collaboration, where agencies work together to meet clients' needs.

Okamoto (2001) explains the purpose of inter-agency collaboration as bridging the gap amongst social service agencies in order to offer clients a wider range of services than a single agency could provide. Guthrie and Guthrie (1990) explain that good interagency collaboration involves "a co-ordinated, case-managed, child-centred system that efficiently and economically serves children and their families with a focus on early intervention and prevention" (p. 3).

A final feature that has arisen from a review of the literature on collaboration is what Head (2003) explains as a deeper purpose to collaboration. He explains that in looking beyond the basic functional benefits of collaboration one might appreciate the meta-cognitive benefits the phenomena can provide. As participants of the collaborative process come together to share, think and feel they are enabling themselves to collectively achieve more than what they could have done as a group of individuals simply working alongside each other (Head, 2003; Walker, 2007). Hildreth \& Kimble (2002) explain this concept as the transfer of tacit knowledge that takes place through collaborative interactions. More learning centred forms of collaboration that exemplify this concept are known as Cooperative and Assisted Learning. A key reason for using these forms of learning, be it for educational, instructional or other purposes (such as conflict resolution), is the motivational benefit they are shown to have on participants (Hickey, 1997; Panitz, 1999). Hickey explains this through Vygotsky's concepts Zone of Proximal Development (ZPD) where participants scaffold upon 
one another's interests, experiences and understandings to create knowledge that increases interest and feelings of adequacy. Collaborative forms of learning are said to increase social skills, honour, feelings of belonging, friendliness, learning and understanding, and to decrease fear, violence, racism, sexism, putdowns, blame and barriers (Yager, Johnson \& Johnson, 1985; Deutsch, 1992; Hickey, 1997; Panitz, 1999).

\section{Collaboration in Action}

\section{Collaboration in New Zealand}

Within New Zealand, collaboration has become increasingly recognised amongst government and non-government agencies as a means to achieving outcomes that address complex social concerns such as youth offending, organised crime, and family violence (Ministry of Social Development, 2003; Atkinson, 2006; Centre for Social Research and Evaluation, 2008; Maori Reference Group for the Taskforce for Action on Violence within Families, 2009; Organised Financial Crime Agency of New Zealand, 2010). Some of the beliefs about collaboration that work as a driving force for its use are that it allows agencies to work together with whole families, rather than separately with individuals of a family (Maori Reference Group for the Taskforce for Action on Violence within Families, 2009). This can help provide a more inclusive public sector that allows for greater efficiency and effectiveness in services (Ministry of Social Development, 2003); it can help foster community development and improve community self-reliance (Ministry of Social Development, 2003) and; it allows for the sharing of information, expertise, and resources (Organised Financial Crime Agency of New Zealand, 2010).

The 'Mosaics' (Ministry of Social Development, 2003) document highlights that while there is evidence that collaboration enriches services through encouraging better processes, improved relationships, a greater capacity to respond to local needs,... more efficient use of resources... and greater community involvement" (p.2), there is not enough 
evidence that collaboration improves outcomes for those the services are intended for. Despite this, with the evidence that there is and the benefits believed to be influenced by collaborative efforts as noted in the previous section agencies are still willing to take it on as a means of achieving desired outcomes and so too provide the opportunity for further evidence to be gathered. Some initiatives in New Zealand have included Strengthening Families (Evaluation Unit of the Ministry of Social Policy, 2001); Youth Offending Teams (Harland \& Borich, 2007), and; E tu Whanau Ora (Maori Reference Group for the Taskforce for Action on Violence within Families, 2009).

A well-established collaborative initiative, Strengthening Families is an example of a whole-of-government initiative that uses case-level collaboration, working alongside a number of both government and non-government agencies across education, health, justice and social sectors. With the aim of moving away from crisis intervention models towards preventive initiatives, Strengthening Families has three key objectives, which are to: increase awareness about the importance of child and youth wellbeing; increase the capacity of families to work together, and with agencies, to solve problems that help improve the wellbeing of their children, and; increase the capacity of agencies to collaborate through using the Strengthening Families model (Strengthening Families, 2010).

A summary analysis carried out in 2001 (Evaluation Unit of the Ministry of Social Policy, 2001) showed that both families and agencies were happy with the outcomes achieved through the collaborative process. Some of the positive feedback related to families being respected and heard, children or youth having improved behaviour and well-being, agencies working well together and with the families, and a plan for future assessment and monitoring in place. Areas that were identified as being in need of improvement included better enabling of families to contribute, holding meetings more regularly, beginning the process earlier, and ensuring more effective means of communication and information for families about Strengthening Families. 
Youth offending teams (YOTs) are an example of a system or operation level collaborative initiative that uses integrated service delivery across government sectors also. YOTs are a result of recommendations made by the Ministerial Taskforce on Youth Offending that to reduce youth offending, immediate attention needs to be placed on "interagency practice, co-ordination and collaboration at a local level, and national co-ordination and leadership" (Harland \& Borich, 2007, section 1:2).

In an evaluation of YOTs effectiveness for improving co-ordination and collaboration at local levels, findings showed that while there tended to be a positive feeling about improved relationships, communication and networking, collaboration was still lacking. Individual feedback highlighted collaboration was either being overlooked or misunderstood (Harland \& Borich, 2007, section 2:2). A key concern Harland \& Borich (2007) address in their evaluation was the need for improved relationships and guidance between YOTs, the Youth justice Leadership Group (the national level overseeing group which includes the Ministers and Senior Officials groups) and the core Youth Justice Agencies. They call for a medium between the top-down and bottom-up models to be found in order to allow for improved leadership and support from the national level that will in turn increase the capacity of YOTS to not only engage and build relationships but identify and address local issues. (Harland \& Borich, 2007, Section 9:2).

In the same spirit as Strengthening Families, the focus of the E Tu Whanau Ora Programme of Action, an initiative developed by the Maori Reference Group (MRG) set up under the umbrella of Family and Community Services (FACS) to provide advice to the government Taskforce for Action on Violence within Families, is on moving away from crisis intervention towards early intervention and prevention. In going back to the different levels of collaboration discussed in the first section of this review, it would seem that regional co-ordination, integrated service delivery, system level collaboration and case-level collaboration are being used to some extent. At the regional coordination level the MRG has 
established what is happening and where to allow for planning and aligning of resources. They use integrated service delivery as they include government, non-government, iwi and hapu organisations in their approach. Working collaboratively within the system of Te Ao Maori and at the case-level they work together to ensure that their collective approach is best suited to the Maori population. The collaborative approach includes a number of professionals from across the country, and extends to iwi and hapu leaders. It is an approach that recognises the need of input from all - professionals, communities, grandparents, parents and youth, and is making provisions to allow for input to be made.

\section{Collaboration for Youth Development}

While the Strengthening Families report gave some idea of youth aimed case-level collaboration in New Zealand, the second part of this section will look more in depth at various initiatives and processes of collaboration for youth with complex needs, both in New Zealand and internationally.

The call for collaboration has come as policy analysts have seen the need for a more holistic, comprehensive, and effective action to be taken for at-risk youth as their problems tend to be complex and multifaceted (White \& Wehlage, 1995; Okamoto, 2001; Beadle, 2009). Okamoto (2001) adds that while collaboration in general is important for addressing youth issues, case-level collaboration is essential for addressing the needs of youth at-risk as it provides individualised services above that which a single agency can provide.

Beadle (2009) explains that despite the awareness above there is little available in the way of services that will deal with multiple concerns in tandem. Instead, what exists is a confusing maze of services available to young people with complex needs. Weist, Lowie, Flaherty, \& Pruitt (2001) raise similar concerns as they explain that in 1999 less than onethird of youth who had mental health needs were receiving care due to a number of barriers which included poor coordination within and between agencies. 
Within New Zealand, Beadle's (2009) concerns have been upheld. While there is much in the way of collaborative initiatives for youth being established (Youth Offending Teams, The National Youth Gangs Project, Break Thru, and The Christchurch Social Policy Interagency Network, to name a few) there is next to nothing in the literature giving evidence of implementation and evaluation or review of such initiatives. Strengthening Families is a successful but rare example of a case-level collaborative initiative for youth development (Evaluation Unit of the Ministry of Social Policy, 2001).

Internationally, there is limited literature regarding successful case-level collaborative initiatives. Two reports that stood out within the literature are Wyles (2007) and Beadle (2009).

Wyles (2007) discusses the success of the Wraparound programme in the United States and its influence on the establishment of the Turnaround programme in Australia. He explains the emergence of the Wraparound framework and how it has developed into what he describes as "a collaborative, individualised, integrated and strengths-based model" (p. 45). From the outset, Wraparound carried the philosophy that planning for care must involve the young person and their family to ensure that the appropriate community services and natural supports were in place. In 2004, the Wraparound framework was refined and 10 key principles were recognised: Family voice and choice; team-based; natural supports; collaboration; community-based; culturally competent; individualised; strength-based; persistence; outcome-based. Overall, some of the significant successes attributed to the Wraparound model include a decrease in negative behaviours, reductions in out-of-home and psychiatric hospitals, increased school and work attendance and engagement, increased school retention and reduction in recidivism.

Due to its success in the United States the Wraparound framework was adopted for use in Australia when a consultancy group for the ACT Department of Education, Youth and 
Family Services described the current system as "uncoordinated and piecemeal in its approach" (Wyles, 2007, p. 47). Wraparound was seen as a Good Practice Framework that addressed a more "whole-of-system" which allowed for a Code of Practice for agencies working collaboratively with young people. As a result Turnaround, an adaptation of Wraparound to suit the needs of young people with intensive support needs in the ACT, was established and select staff from all government departments and relevant community networks were trained. Turnaround holds the principles of genuine involvement from young people and shared responsibility across government and non-government through collaboration in highest regard. Using a mixed methods approach, Turnaround was evaluated after two years. While it was suggested that more time was needed to truly understand the programme's effectiveness the majority of young people responded positively to the programme and were on board with a system they previously had apprehensions toward. Turnaround had a positive impact on addressing the barriers for family contact, school and employment, and accommodation.

In Australia, Beadles (2009) work is a review of Youth Substance Abuse Services YSAS), and how they go about achieving a holistic approach in addressing the needs of young people. Through staff interviews Beadles found that at the heart of their work is the belief that in order to help a young person through their substance abuse the worker needs to know the individual's story. The worker needs to understand the multiple and interrelated factors that influence the abuse which obstructs the young person from being able to take control. To achieve this there are no pre-determined stages that workers go through with their clients. Instead, Beadle found a number of key components that workers adhere to in order to create a holistic approach. These are: fitting the intervention to the client; harm minimisation; building relationships of trust and support; active engagement of the young person in the intervention, and; collaboration with other services. She explains how collaboration with other services is central to each of the other factors. Workers collaborate with the young 
person and their family to make an intervention individualised, and they work with other agencies to gain information and services they cannot personally provide. The key worker acts as the common thread by transporting and standing by the young person when meeting with these different agencies, and they continue to work alongside the young person as they move forward together.

Each of the programmes discussed had similar guiding principles that led to their success in providing holistic interventions for their youth cliental. Each saw collaboration as a key factor for addressing the multi-faceted needs of their youth, each ensured that interventions were individualised, and each held the young person in high regard as a key player in the process. A key difference which stood out was Turnaround's training, including members from all government agencies and other community organisations (Wyles, 2007). Perhaps this is something that YSAS could look at to address concerns around working with other services.

While this section of the chapter has highlighted the limited literature around caselevel collaboration for youth development not only in New Zealand but in Australia and the United States, it has also highlighted that positive results are coming out of what little there is. One might conclude that because there is a lack of literature there must be a lack of collaborative work happening on the frontline of youth work. Another possibility is that while there is a lot of work going into more holistic approaches, limited funding and resources could mean that money is going directly towards programmes rather than evaluations and reviews that would give evidence of its implementation.

\section{Factors for Success and Challenges to Overcome}

Despite the lack of findings relating to actual examples of case-level collaboration, there is a fair amount of literature relating to the 'do's and do not's' of collaboration. Beadle (2009) highlighted the frustrations that YSAS workers feel when they are met with barriers to 
their collaborative efforts due to organisations being inflexible. One worker states that, “... a lot of my time and effort that I get paid for by the government goes into trying to work with other government organisations" (Beadle, 2009, p.27). As this seems to be a common and overriding challenge to collaboration, there are numerous suggestions as to why this is so, most of which come under the umbrella of excessive bureaucracy (Guthrie \& Guthrie, 1990; Weist, Lowie, Flaherty, \& Pruitt, 2001). Challenging factors that can be seen to fit under this umbrella include: using narrow definitions or labelling, drawing boundaries, and fostering autonomy (Beadle, 2009); power struggles due to differing agendas (Walker, 2007); turfism (Weist et al., 2001) and; an excess of jargon (Guthrie \& Guthrie, 1990).

Guthrie \& Guthrie (1990) explain that letting go of bureaucracy and organisational musts is imperative if initiatives are to be child-centred because it allows for putting the child's needs before processes. In the same spirit, Beadle (2009) discusses a recent review carried out in Victoria, Australia which emphasizes the need for a local generalist youth service where youth workers can work across the board to assist young people without meeting bureaucratic and organisational barriers.

Aside from the bureaucratic barriers, some challenges to achieving successful collaborative outcomes are of a more physical nature such as work schedules, the ratio of need verses resources, limited staff, and trying to make a time that works for everybody (Weist, et al., 2001). Other challenges might be seen as a result of poor attitudes which lead to: defensiveness, negativity and poor co-ordination within and between agencies (Weist, et al., 2001); diffusion of responsibility, blaming other agencies for youth's failures, withholding information between agencies, agencies covering up mistakes, and premature termination of collaborative efforts (Okamoto, 1990); fear of negative ramification from other colleagues when making controversial decisions, financial liability, accountability for treatment decisions, fear of youth themselves, and fear of organisational change (Okamoto, 
1990); lack of knowledge (Guthrie \& Guthrie, 1990; Weist, et al., 2001), and; all talk no action (Guthrie \& Guthrie, 1990).

With the many obstacles to collaboration coming from both ground and organisational levels there are also many suggestions for opening up paths to success. In an attitude of optimism, Guthrie \& Guthrie (1990) state that, despite the obstacles, the time for discussing whether or not to collaborate has passed and that now is the time to work out how to make it happen efficiently and economically. In a similar attitude, Weist, et al., (2001) argue that while the barriers they acknowledged are real, if people truly appreciate the value of collaboration such obstacles could be overcome.

Weist, et al., (2001) explain that turfism, defensiveness and negative attitudes can be overcome as professionals learn and understand one another's differing roles and expertise. They explain that this will further benefit collaboration as resources are more likely to be used to their potential and potentially sabotaging misunderstandings can be kept to a minimum. They advise that unless that base of understanding is in place relationships that promote positive working partnerships will not be achieved. Beadle (2009) makes similar recommendations through two of her six guidelines for improved collaboration: promote collaborative values amongst professionals through training, and: familiarise workers with the other services available in the local area.

Beadle's (2009) other recommendations are to: invest in on-going research on the service situation (it is important that this involve expert advice from those on the frontline, namely youth workers and young people); invest in new infrastructure, such as a generalist youth service; provide youth services with a dedicated and on-going funding stream, and; facilitate better communication between practice, research and policy. In regards to the new infrastructure of a generalist youth service, Guthrie and Guthrie (1990) explain that due to tight funding and the economic state, it would seem more practical to just improve collaborative efforts through current youth service agencies than to set up a whole new 
scheme. With the economic recession of recent years and further threats to it in the first quarter of 2011 already, this may be sound advice.

Finally, just as there are numerous challenges to case-level collaboration the literature also outlines many factors for success, which include: cooperation and communication (Okamoto, 2001); comprehensive, preventative, child centred, and flexible (Guthrie \& Guthrie, 1990); family voice and choice, team-based, natural supports, collaboration, community-based, culturally competent, individualised, strength-based, persistence, outcome-based (Wyles, 2007).

As Beadle (2009) implores, despite the challenges surrounding collaboration policy makers and professionals need to persist in efforts to make it a priority approach to youth issues. Moreover, programmes for youth intervention and development need to appreciate the importance of interdependence. She explains that while there are good models such as Wraparound, no one model will suit every community or organisation. Guthrie \& Guthrie (1990) suggest that interagency collaboration is going to work differently for every community and so any model that may be introduced must be adapted to work effectively from one community to another.

\section{Contributors to the Collaborative Process for Youth Development}

The literature thus far has suggested that a key benefit to collaboration within the social sector is that it allows for all the agencies involved with a person to bring their resources and expertise together to work more efficiently and effectively. It can be understood that depending on each person's different needs, the agencies that are involved vary from case to case. Most of the literature relating to collaboration within New Zealand focuses only on the agency and organisational levels, leaving out those receiving services and sometimes even the frontline staff who provide the service. Furthermore, with the limited literature relating to collaboration within youth related programmes there is even less that 
discusses contributors to the collaborative process in any depth. However with the review of literature relating to collaboration in youth development above it can be seen that aside from agency professionals there are others to be taken into account for the contributions they have to bring to the collaborative. The literature below looks at who else should be involved in collaborative processes when working with youth, and why.

Spergel (2005) explains that collaborative interventions for youth should include schools, youth agencies, police and the key person in the picture, the young person. The success factors for youth services discussed above also highlight that active involvement of the young person is key to ensuring outcomes that work for and empower them to drive their change (Guthrie \& Guthrie, 1990; Wyles, 2007; Beadle, 2009). The empowerment comes in shifting the outlook from them having problems to be fixed by a professional, to them being mentored into taking control of their future (Beadle, 2009).

Beals (2006) highlights the lack of youth voice in academic literature and youth policy as she explains that none of the definitions and constructs she introduced above relate to how youth see themselves, which is often in contrast to how adults view them. She explains the constructions that adults and societies make about youth as a form of gaining power over young people, forming a degree of inequality and empowering themselves to enforce authority. She further explains that even when claiming to empower youth to take responsibility and participate in certain matters, there are often adult-imposed guidelines regarding how much a young person may contribute, or what kind of young person will be heard. Fattore et al. (2009) reinforce this concern stating that literature generally does not take into account perspectives of young people on matters relating to them.

A key concern raised by Beals (2006) that comes out of the lack of 'youth voice' is the misinterpretations and misunderstandings that evolve through leaving them out of the discussion. She introduces the concept of 'the socially-created deviant'. Similar to the conceptual understandings explained, the 'socially-created deviant' notion comes from 
sociological theory which explains youth deviance as a construct of the society that defines it. It relates to labelling and stigmatisation, put in place by societies to define what should and should not be acceptable. This is similar to the concepts raised by Gergen (2009) under the poetic principle of Appreciative Inquiry. While such practices can highlight the need for intervention in cases of problematic behaviours, they do not necessarily address the motivation and background to behaviours, nor why society sees them as problematic in the first place. In some cases problematic behaviour is generally universally accepted, such as violent outbursts causing harm to others or self. Other behaviours, however, such as poor socialization skills and attention deficit order which are often described as problematic and sometimes included in risk-assessment are not so straight-forwardly justified (reference).

From a more positive angle, Mitra (2004) reveals a number of elements that highlight the importance of youth themselves being involved in the collaborative process as she discusses the significance of 'student voice' in schools and the impact that it has on youth development. 'Student voice' is a concept that she explains is being increasingly discussed in school reform literature in the United States both because of its benefits for improving student outcomes and for school restructuring. The mind-set behind 'student voice' is that to address student outcomes you need to go to the source, the students. She explains that as students are included in information sharing activities, teachers and administrators are reminded of the unique and important insights that only students can provide. In recognising this and allowing open conversations to happen, issues such as equity, attendance and school failure can more appropriately be addressed and schools will better appreciate their own accountabilities. The implementation of 'student voice' in some schools has resulted in improvements to teaching, curriculum and teacher-student relationships. Camino's (2000) exploration of youth-adult partnerships adds to this understanding of the mutual benefits that can be achieved when youth and adults work alongside one another. She explains that such 
partnerships signify innovation in community development as mutual respect and understanding are enhanced.

Along with the benefits that 'student voice' has on whole-school outcomes, Mitra (2004) looks at whether 'student voice' can have a direct impact on an individual's youth development. Her interest in this study is along similar lines to the concept discussed by Hildreth \& Kimble (2002) of the learning process that takes place through interacting and sharing with others. Mitra's findings gave evidence that where student voice was practised, youth developed increased agency, belonging and competence. More specifically, agency was increased through increasing ability to articulate opinions to others, constructing new identities as change makers, and developing a greater sense of leadership. Belonging was increased through developing a relationship with a caring adult, improving interactions with teachers, and increasing attachment to the school. Competence was increased through critiquing their environment, developing problem solving and facilitation skills, getting along with others, and speaking publicly.

Although Mitra's (2004) work is school-based, Camino (2000) further highlights the empowering effect that working alongside adults in an equal and respected manner has on youth. She explains that youth work theory and practice are now moving away from a protective emphasis towards promotive actions such as can be seen when they are given responsibility and respect for what they have to bring to the table. Mitra's work not only gives evidence of the developmental benefits to encouraging youth voices in initiatives for change, be it organisational or personal, it also clearly outlines ways of achieving this.

Further to youth being key contributors to the collaborative, Spergel (2005) additionally highlights the need for parent and neighbourhood involvement. Disjuncture is a term White \& Wehlage (1995) use to describe poor policy that was implemented due to a lack of understanding and knowledge about communities in which the policy was intended for. A key point that White \& Wehlage raise in relation to disjuncture is that collaboratives 
were dominated by professionals and executives who naturally focussed on "executive-level" problems rather than focussing on the ground level communities concerns. This top-down approach was recognised by local community members as just another group of outsiders trying to fix problems they did not understand. In regards to youth development, disjuncture can happen when youth, families, or frontline staff, are not involved in decision making processes.

White \& Wehlage (1995) further explain the need for collaboratives to focus on building social capital if they are going to make any impact on youth and communities atrisk. They explain the cause and effect relationship between a decline in social capital and an increase in crime and anti-social behaviours. The authors state that in order for any social service agency or collaborative to be successful in assisting struggling youth and families the core focus must be on the community it aims to serve and not the institutions. Furthermore, they express that the top-down approach will never work in such efforts as community involvement, and understanding of their needs as seen by them is essential.

While White \& Wehlage (1995) speak from the American experience, an example of this concept of client, family and community involvement can be seen through a study carried out by Bishop (2005). Bishop looks at the role culture plays in a students' intrinsic motivation and feelings of belonging at school through an enquiry into discourses of Maori students' school experiences. His findings identified feelings of not belonging, having low expectations placed upon them, and a lack of respect for their Maori heritage. He particularly raises the concern that when youth see that their parents are not involved in or supportive of the school there is a direct effect on the youth's attitude towards school. He explains that while teachers, and in this case youth and community workers, need not be multi-cultural experts, in order to better understand and have a positive impact on young people they need to build relationships with the whanau and their community. 
Wyles (2007) further emphasises the need for collaboratives to involve youth, their families, and other natural supports in a culturally competent manner. This is particularly pertinent in New Zealand as Maori youth continue to be hugely over-represented in both Police apprehension and criminal prosecution statistics (Ministry of Justice, 2010b). Osborne (2004) coined the term 'disidentification' to sum up the idea of cultural misunderstandings in the education sector which can be extended to the youth sector more generally. He explains that it is the feeling of disidentification that influences the resistance to school and education often displayed by students of minority cultures. Furthermore, Majors and Billson's 'cool pose' theory (Wearmouth et al., p.63) describes how young men of minority cultures may act out with non-conformist behaviour as a survival technique from social oppression within the classroom. Mitra (2004) further explains that when students are viewed as clients that a distance is created which invites feelings of alienation and powerlessness. She explains that such feelings cause students to become disengaged at school which can lead to cutting class and dropping out. In order for successful outcomes to be achieved through collaboration, youth and their families must be seen as equal partners with just as much to bring to the table as any other professional in the room, otherwise the group runs the risk of causing them to feel more excluded and dependant.

Again with a New Zealand perspective, Hynds (2008) explains how directly involving the young person and their supports, be it whanau or other, in the collaborative process can enhance cultural competence as professionals experience the emotional "buy in" called for by Guthrie \& Guthrie (1990). Having listened to experiences shared by students of minority cultures about their feelings towards school, teachers, and teaching methods, teachers acknowledged a desire to take responsibility rather than pass judgement or blame and to reconsider their teaching methods in order to better accommodate those students who they had not previously understood. While Guthrie \& Guthrie suggest that staff need to be given greater scope to step out of the boundaries of their job descriptions so that they can get out of 
the workplace and into the communities and homes of their clients, the above literature implies that further boundaries need to come down to encourage families and communities to also come in, be it in the literal sense or figuratively.

A final benefit of involving both youth and their families, or other natural supports, to the collaborative process is that despite youth having moved into adolescence and finding a sense of independence, parents continue to matter (Steinberg \& Duncan, 2002). While it is understood that many youth risk-factors may stem from the home and some youth may not sense a great deal of belonging or protection from their family, involving both parties may allow opportunities to bridge existing gaps. This may be achieved in two ways; the first comes from Camino's (2000) explanation of the growth of respect and understanding that can come out of youth and adult partnerships. As parents and child work alongside one another within a collaborative there is the opportunity for each to gain insights from one another they may not have previously picked up. The second way that relationships may be mended or strengthened is by increasing the capacity of parents or families (Steinberg \& Duncan, 2002). As parents work alongside both their child and other agencies in a collaborative not only may they be enlightened with greater understanding about their child and his or her needs but they will likely also gain an increased understanding of the resources and help that is available to them as parents. In building relationships with professionals from different agencies, parents are more likely to feel comfortable in going to them for help and advice.

\section{Summary of Literature Review}

The above review has highlighted the complexities surrounding youth and collaboration. While there is a general consensus that collaboration is necessary for successful youth development programmes and services it is clear that achieving good collaboration entails many challenges. Aside from the bureaucratic factors highlighted, one of the greatest challenges seems to be a lack of understanding and mutual agreement within a 
group regarding what collaboration entails. Perhaps one reason for this that can be seen in the review above is that there are various definitions and levels of collaboration. With the varying levels of collaboration, it would seem necessary that the first task programmes and organisations need to carry-out is to decide on the type of collaboration they wish to engage in to achieve desired outcomes. Once this has been established outlining a clear definition of collaboration, who should be involved and what processes might be followed will be easier. Finally, the review has made it clear that the best collaboration involves all parties interested in the outcomes of the process. That is, it is not simply a process that professionals should be undertaking amongst themselves for more effective and efficient outcomes, but rather by enlisting those who the services are aimed to help, the process will not only become more meaningful but is more likely to be put to good use and achieve results. 


\section{Chapter 4 Methodology}

This chapter provides an outline and explanation of the research methods used for my study. In the first section I explain my choice to use the phenomenological approach for carrying out a qualitative study to answer my research questions. The next section provides a rationalisation of my methodology, followed by a section outlining in greater depth the methodological approach I have used. In the second half of the chapter I introduce the participants for my study and my processes of data collection and analysis. Finally, I address accountability and trustworthiness and ethical considerations.

\section{Method}

The study will be carried out using qualitative research through a phenomenological approach of interviews using key principles of Appreciative Inquiry (AI). With qualitative research focussing on an in-depth examination of a small number of independent cases, the purpose of phenomenology is to better understand and explain people's experiences of a particular phenomenon(Johnson \& Christensen, 2007). The phenomenon of interest for this study (which will be looked at from a youth perspective) is collaboration within youth development programmes in New Zealand. Johnson \& Christensen explain that phenomenological study seeks to explain through a rich and descriptive report the meanings, structures, and lived experiences of the phenomenon as shared by the individual participant/s.

While it has been argued that qualitative research designs such as case-study utilizing phenomenology are limited and un-generalizable due to their small sample size, Flyvbjerg (2006) contends that this argument comes from a lack of understanding about human learning. To explain this, he discusses concepts of context-dependent and contextindependent learning. Where context-independent learning relies solely on rote and analytical rationality, context-dependent learning relies on experience. As hands-on experience builds tacit knowledge, Flyvbjerg argues that it is through context-dependent learning, that one truly 
becomes an expert in a field. Lee, Mishna, \& Brennenstuhl (2010) add that with the increasing call for evidence based-practice (EBP) in social work, these qualitative forms of research perhaps provide the best evidence to guide practitioners as they require intense investigation of empirical data. Phenomenological study therefore appreciates the importance of personal experience for building knowledge to be used for improving processes and structures that effect people.

AI is focussed on eliciting the strengths of people and organisations so will enable myself and the participants to both consider what has worked for them in regards to collaboration previously, where they feel improvements could be made, and how they believe collaborative processes might best work for them. AI appreciates that with any one phenomenon there will be a number of varying experiences and perspectives dependent on a person's positioning within that phenomenon. While the youth perspective is just one of many that may be involved in a collaborative approach, this research is anticipated to be the initial stepping stone for potential future research to be carried out.

\section{Rationalisation of the Methodology}

It is my belief that the only way of really understanding whether youth services are successful in improving youth development within New Zealand is to go to those receiving the services and learn from their experiences. The phenomenological approach allows me to gain such insight from young people as they share their experiences and insights regarding collaboration within the services they have received. As the literature explains that the collaborative approach ensures that all the needed resources and services are available for meeting the multi-faceted needs of youth-at-risk, I am interested in knowing whether youth feel they have been involved in or recipient of such an approach and if so whether they feel such an approach has been beneficial. 
Having been a youth worker myself and understanding the complexities of making collaboration happen I am aware that there is no one way of carrying out the approach. As each region in New Zealand has different services available with a mixture of both government and non-government organisations, each will vary in what they can offer to youth and how they go about that. This means that it is likely that no one participant's experience of collaboration is going to be the same as the next. Carrying out in-depth interviews with the young people will allow me to get a good grasp of how each of the varying services they are involved with work for them and at what levels collaboration is happening. This will be achieved by discussion and probing for clarification on points that I am not sure about. Furthermore, it will allow the participants the opportunity to ask me to clarify any points that are not clear to them also. The ability to discuss and clarify through the interview process will ensure that I have properly understood responses and experiences of the youth participants so that I make the most correct representation as possible of what they have to say.

A key motivation for my choice of the AI framework is that it allows the voice of the participants to be heard in an empowering way. In my personal experience as a youth worker it often felt like policy was being made by people who were detached from the grass-roots experience: for example, government ministers who have been given a portfolio with agendas to meet and successful business men or women that chair trusts and insist that a business model be used to revamp the programme. While this may not always be the case, the gap in literature regarding youth experiences of collaboration in programmes intended for their benefit is evidence enough for me to see the need for the youth voice be both expressed and heard. It is hoped that the findings of this research will be an intrinsic motivating factor to practitioners and policy makers alike in considering the need for a more in-depth exploration of collaboration for youth development in New Zealand to bring about change. As has been noted in the literature review (Guthrie \& Guthrie, 1990; Hynds, 2008), adults have a change 
of heart when they truly understand where a youth is coming from through hearing young peoples shared experiences.

\section{Methodological Approach}

Cooperrider \& Whitney (2005) describe the process of positive questioning as an art. Like most qualitative forms of research there is not a structured step by step guide to using Appreciative Inquiry. There is however a guide that ought to taken into consideration if one is to be successful in fully unleashing potential outcomes. This guide is known as the 4-D cycle. Following the 4-D cycle will ensure that a collaborative process of questioning, sharing, reflecting and taking action is carried out that will enable long term change. The 4-D cycle covers four stages of inquiry, they are: Discovery; Dream; Design, and; Destiny. If one imagines this cycle as a circle of stages, at the circle's centre is the 'unconditional positive question', also known as an affirmative topic choice (Cooperrider \& Whitney, 2005). Just as has been explained that the kinds of questions asked determines the direction an organisation will follow, Cooperrider \& Whitney (2005) emphasize the importance of the 'unconditional positive question' for guiding the potential of a project.

The first stage of the 4-D cycle is discovery. Cooperrider \& Whitney (2005) describe this stage as 'mobilizing' the inquiry. It includes finding the affirmative topic choice, that is, an unconditional question that hits the spot of both determining the desired outcome of the research and addressing it in optimistic tone. With an affirmative topic choice determined the next step is to address what is already working in relation to the matter. This is achieved as those involved share stories of their experiences that illustrate positive aspects of the organisation in relation to the topic. In essence, it allows participants to discover what is working but may have been overlooked in focussing too much on what is not working.

Once an appreciation of what is has been reached, the next step is to consider what more could be, or in other words, to dream (Bushe, 2005; Cooperrider \& Whitney, 2005). 
There are no boundaries placed on this stage, no limits or exclusions as to who can propose the possibilities or what they may be. A key to having all participate in the Appreciative Inquiry is that members of the group feed off one another. Through previously having heard one another's experiences and stories, they have a better understanding of backgrounds and reasoning for outlooks and suggestions, and as a group with a collective affirmative topic to address they will begin to build common ideas and dreams for the organisation. The idea is that as the organisation begins to appreciate their true potential when limiting barriers are broken down and thus understand their higher purpose, they will create an outcomes based vision for themselves (Cooperrider \& Whitney, 2005).

As the vision unravels the next stage of the cycle comes into play. While the term design generally suggests thoughts of calculated structure and outlining of clear definitions, in terms of Appreciative Inquiry it is more the notion of considering possibilities for implementation of the unified vision. Bushe (2005) explains this well as he tells how the final ' $\mathrm{D}$ ' in the cycle used to be 'deliver' but it was realised this created further validation and accountability exercises to the process. Creating further tasks decelerated the momentum and motivation that had been achieved through involvement in the earlier stages due to forgoing the familiar hierarchical structures and decision-making processes. So, the design stage is to craft "possibility propositions" (Cooperrider \& Whitney, 2005) that will enable the "positive change core' and allow participants to see how the dream can become a reality.

The destiny stage then is essentially enabling momentum and motivation to build through continued strengthening of the affirmative experience through allowing members to take initiative to bind their work with the unified dream, making adjustments, improvisations and implementations as they see fit. For most people who have had even just a small taste of professional, personal or organisational development this notion of resisting a plan of action may seem disconcerting as it is a general rule that when setting goals you write them down and make a plan outlining how you are going to achieve them. For AI however, the destiny 
stage requires sustaining the vision and momentum through being able to make adjustments and improvisations along the way. Having set tasks can obstruct these needs for flexibility. It should not be misunderstood that this means that the destiny stage is about just hoping that everyone is now on the same wavelength with each other and is to be left to their own devices. Rather, this stage is about continued momentum through learning, empowering and constant shared effort. In the words of Cooperrider \& Whitney (2005), “organisation change needs to look a lot more like an inspired movement than a neatly packaged or engineered product" (p. 12).

\section{Participants}

Recruiting participants for this study proved to be one of the greatest challenges of the task at large. This was not due to individuals being disinterested but rather it was due to organisational ethics and bureaucracy. My initial intention was to carry out Appreciative Inquiry in its usual group format with not only youth but youth workers, managers, families, and other services involved. With my familiarity with Police YDPs and the knowledge of their effort to be more collaborative in their approach, I had hoped to invite three programmes from different regions in New Zealand to participate. While I had made contact with a couple of programmes to gauge initial interest, and had received a positive response, before making official contact and organising the inquiry to take place I had to first go through the Police Research and Ethics Committee. The committee required a proposal that outlined what the research was about, who was required to be involved, how much of their time it would take, what their role would be within the study, and so on. Having jumped through all the bureaucratic hoops and going back and forth with the required adjustments and additions to the proposal I was then told that due to members of the committee being on leave my application may not be responded to before Christmas. With the time constraints of a Master's thesis, waiting another month just to know whether I would be approved to 
officially invite programmes to participate was not reasonable. Having lost literally months in the above process I decided I had to both pull back on my scope and find a way of recruiting that would not involve going through another application process.

Reflecting on the lack of studies on youth experiences of collaboration that I had noticed when carrying out my literature review I decided that by focussing on youth only I could address this gap. This would further ensure that the only people who would be required to consent to me carrying out the research would be the young people themselves and, depending on their age, maybe their parents. Whilst I would no longer be able to use the AI framework as I had initially intended I felt it was still an important aspect to the overall thesis. I decided to use the 4-D cycle as a guide for my interviews to illustrate how simple yet effective it can be in the context of organisational inquiry and change.

With the focus of this study being on collaboration within youth development programmes, or similar youth services aimed towards youth labelled "at-risk", participants were invited to share their stories due to their current or previous involvement in such a programme.

Although the Ministry of Youth Development (2005) outlines the age of youth as young men and women aged between 12 and 24 years old, within this text I have chosen to define youth as those between the ages of 10 and 18 due to their general eligibility for involvement in youth development programmes. Participant eligibility however included young men and young women between the ages of 10 and 20 years old so as to get the greatest amount of feedback possible. This was justified as those who have only recently completed involvement with youth services would likely still have experiences fresh in their mind and a maturity to reflect and respond insightfully.

In regard to sample size, the nature of phenomenology means that the quality of empirical data is more important than the quantity of data. Johnson \& Christensen (2007) explain that phenomenology strives to explain how a person or people experience a 
phenomenon. While generalizability is not a priority of phenomenological research, due to the range of youth services and YDPs that exist within New Zealand I wanted to have a sample that acknowledged the differing approaches various regions offer so that my findings might be more transferable to the various initiatives. To ensure this, it was my intention to have between six and ten participants involved from at least three different agencies in different parts of New Zealand. To achieve this, I was reliant upon agency referrals which I gained through contacting a number of youth development programmes and similar services by phone and explaining my intentions, followed by a more in-depth email. I was eventually successful in recruiting seven participants from three different youth programmes in the lower North Island of New Zealand. Through personal networks I was able to recruit a further two participants who had recently completed involvement with youth services in Auckland and Dunedin respectively. Participants included four girls and five boys aged between fourteen and twenty years old with a mean age of sixteen years. Participants were made up of those with Maori, European, Niuean, Samoan, and Cook Island descent, with seven out of nine participants being part Maori which offers a fair representation of voice to the current unfortunate statistics of the target population as found in the report by the Ministry of Justice (2010b). All nine of the youth were or had at some stage been living away from their parents under the care of either extended family or some form of youth service.

A common concern raised by youth workers in the process of recruiting participants was that youth not be known for the poor decisions they had made or the challenges they faced. They did not want their youth to be treated as a statistic. It was therefore important for me to be able to assure workers, prior to them referring any youth, that not only would the study be strengths-based but that there was no need for me to know why youth had become involved in programmes or services. I simply wanted the young persons' feedback regarding their experiences. If participants felt it important to share further with me to better explain themselves then that would be their choice but I did not feel that such information was 
important enough to the outcome of the study to make it a focus. I later found that this further helped me to build rapport and gain the information I sought from participants as my sole interest was in what they had to say, not in trying to label or define them. This was important as they were able to see my genuine respect for them as people and interest in their experiences.

So as to ensure confidentiality, pseudonyms have been used in place of real names. Youth were given the opportunity to come up with their own names or have one made up by myself.

\section{Data Collection}

Data for the study was collected during in person interviews. Although AI is generally used in a group context that invites all to share and hear together, because I wanted to gain the youth perspective I have used a one-on-one interview approach to draw out as much as I could from individual participants. Carrying out interviews in person better allowed me to build rapport with the youth as they could see me as a real person, not just a name or voice at the other end of the phone. It meant that I was able to share my own experiences as a youth worker that influenced my choice to carry out the study, why I wanted to hear what they had to say, and how I hoped that it might benefit youth in the future. Building a rapport and allowing them to ask any questions they had before beginning the interview further allowed me to adjust my tone and approach to ensure I met them at their level of conversation and understanding. While seemingly small things, I believe this approach allowed for me to gain a greater depth of knowledge from them than I would have through any other means of contact. Furthermore, the in-person interview allowed me to probe, clarify (sometimes through drawing diagrams), and read their expressions to ensure better understanding and interpretation of their information was carried out. 
Interviews varied between fifteen to forty-five minutes depending on how much youth had to share with me. Interviews were recorded and later transcribed by me as principal researcher so that they could be examined as much as needed to gain a full understanding of responses and carry out a cross-case analysis looking for common themes. Notes were also taken during the interview.

Johnson and Christensen (2007) explain that qualitative interviews can be approached in one of three ways - the informal conversational interview, the interview guide approach, and the standardized open-ended interview. With a set research question and sub-research questions already highlighted it was important for me to have an outline of interview questions that would ensure the interview stayed on track but at the same time be flexible enough to let the young person guide the flow of the interview. For this reason I took the interview guide approach. As my aim was to bring out aspects of the AI 4-D cycle through the interview process questions were ordered with the four phases in mind and presented in such a way that invited youth to both share their stories and consider how they might like to see services rendered to them in the future. The affirmative topic choice (or unconditional positive question) was outlined within the purpose of this thesis in chapter two. The purpose of this study is to discover how collaboration might be improved to better focus initiatives to the needs of young people.

In the first phase of the interviews I posed questions that invited youth to share their experiences of 'what is' with regards to the youth services they have been and are currently involved with. We then moved into the dream phase as I invited them to consider 'what could be' with questions that required thinking about how a collaborative approach could work better for them. This included questions regarding who they felt should be involved in a collaborative team with them and how that team might work. With the purpose of the third stage being to design possibilities, once the young people had shared how they saw collaboration working for them, I had them consider whether their dreams were something 
they felt could become a reality and if so how. Finally, with the destiny stage in mind my closing questions invited youth to appreciate the role they personally play in their own development within the youth services and encouraged them to own that role by taking it upon themselves to contribute to the collaborative process.

Below is the interview guide I used, divided into the four phases:

\section{Discover}

- Does the word collaboration mean anything to you? If so, what?

(Clarify the meaning of collaboration)

- Do you feel you have benefitted from any level of collaboration in your involvement with youth services in New Zealand? If so how?

- Who are some of the people that you feel have helped you develop as a young person? (this can include professionals and non-professionals)

- What have these people done for you to help you develop?

- Is it important to you to have support people around you in your development as a youth?

\section{Dream}

- If you could make up a collaborative team to support you in the different areas of your life that you feel are important to you, who would you invite on board?

- What are some of the different areas of your life that are important to you?

- What areas of your life do you feel it is important to have support in?

- Having thought about this further, would you change anything about the collaborative team you described earlier?

- How do you imagine a collaborative team would work? (e.g. would you just go and ask for help when you needed it? Would you meet together as a group? Would a specific person run meetings?) 
Design

- Do you feel you have the resources available to you to make this collaborative team come about? Discuss.

\section{Destiny}

- What would it mean to you to have a team in place specifically to help you develop in all of the areas you mentioned earlier? Discuss.

\section{Data Analysis}

With the purpose of phenomenological study being on understanding experiences, it is critical that the analysis of data be thorough to ensure that correct interpretations and representations are made. Hycner (1985) explains that while there is no 'cookbook' procedure for carrying this out, there are some guidelines that, if adhered to, will ensure the researcher stays true to the phenomenon without interfering presuppositions whilst also being able to address the outlined research questions. These guidelines include: recording and full transcription of interviews; listening first simply to the story - not for meaning and answers as many times as is needed to begin to feel in the world of the interviewee; avoiding presuppositions or biases; getting a sense of the interview as a whole; look for meaning; look for any relationships between meanings and the research question; look for common themes as well as individual variations amongst interviewees. Johnson \& Christensen (2007) explain well the need for thorough analysis in qualitative research, in particular the need for appreciating the participant's story before attaching personal theories and biases to it. Researcher bias is a threat to the validity of research and therefore thoroughness in both ensuring that stories are properly understood and interpreted and that critical self-reflection regarding potential biases is carried out is crucial. The result of such a thorough analysis of 
data should be that of a rich narrative report that describes common characteristics of the phenomenon in a way that addresses the research question but is not necessarily limited to it (Johnson \& Christensen, 2007).

One bias that I was alerted to on reflection of the interview process was that while I have been particularly interested in the holistic approach and all the different areas a young person should be getting support in, their requirements for support tended to be much more straight-forward. The second bias was that I was so concerned with the obstacles to collaboration from a professional perspective, that I had not even considered that many of the simple acts of collaboration, such as within multi-service agencies, could still have a positive impact. The final bias that I was alerted to in my self-reflection was that again, from a professional/academic point of view I have been focussed on the practicalities and processes of collaborative practice and overlooked to a large degree the relational impact of collaboration.

To ensure thoroughness in my analysis I have made an effort to acknowledge the guidelines set out by Hycner (1985). Having carried out all nine interviews within a twoweek time frame the common themes that arose amongst participants were quickly apparent. It also allowed me to use what I had learnt from one interview for the following ones - for example, questions that perhaps I thought that were clear that were not I was able to re-word and address with a different approach for the next interview. Furthermore, in personally transcribing each interview within days of completing them, gestures and mannerisms were still fresh in my mind. Having particular responses and tones reinforced within the short timeframe made revising the interviews that much easier. A final benefit of carrying interviews out within the compact time-frame was that I quickly adjusted to the young people's level and so was more easily able to get myself into their world, appreciate their way of thinking.

In one instance I had to go back to a young person to revisit a point that I had not gained enough information about the first time. This act proved to be critical in that the extra 
information gained highlighted an exception amongst the majority in regards to a common theme.

To ensure interpretive validity (Johnson \& Christensen (2007) I sent notes on findings that were relevant to individuals back for their confirmation, or correction, before finalising my findings and discussion.

\section{Accountability and Trustworthiness}

In carrying out this study I will be accountable to all those who share their stories. All participants were provided with an information sheet outlining the research at hand and what was to be required of them before gaining their written consent to participate. The information sheet further outlined the potential for publication of this thesis, that is, that both hard and electronic copies of the thesis will be held at the Victoria University library and that it may be used for dissemination at academic or professional conferences and/or published in academic or professional journals. Furthermore, any youths aged 14 and under were required to gain parental consent prior to consenting themselves to participate.

The first priority of the interview session was to re-ensure that participants are clearly briefed and understood the process and purpose of the study and that they were free to withdraw from the interview at any time. Keeping in mind that the study has used a phenomenological approach based on young peoples' personal experiences, it was imperative that interpretations of meanings were taken back to participants for their approval that I had understood and interpreted what they said correctly so as to make a fair representation. Transcriptions of interviews were returned to participants for their approval prior to the study's completion to ensure meanings have not been altered or misunderstood.

Johnson \& Christensen (2007) explain the one way of ensuring accountability to the participants' stories is in using low-inference descriptors that will allow readers to experience the actual language and dialects used so that they too might more fully appreciate personal 
meanings. As verbatim is the lowest inference descriptor of all, I have made a point of using direct quotations to explain my findings.

\section{Consideration of Ethics}

The ethical requirements and guidelines of the Faculty of Education Human Ethics Committee, Victoria University, Wellington, will be adhered to. 


\section{Chapter 5 Findings from the Youth Perspective}

Along with having my research questions answered, a common theme around relationship building arose in all interviews giving significant implications for youth services in New Zealand. Within this chapter I will address the sub-research questions outlined in Chapter 2 regarding participants' levels of involvement with services, experiences of collaboration, and preferred teams. Aspects of relationship building will be discussed as they arise within the findings. In the final section of this chapter I will address the main research question through a summary of the previously established findings.

Sub-Research Question 1: What type of involvement has the young person had with youth development services in New Zealand?

Before addressing the data in this section I wish to reiterate that as the purpose of this study is to look at youth perspectives and experiences of collaboration, interviews did not focus on why youth were involved in youth development programmes or similar services in the first place. The flexibility of the interview approach meant that should they feel to, they could offer up such information but as the interviewer I was not going to force it as I wanted to keep interviews as strengths-based and comfortable for the young person as possible.

With regards to formal programme involvement, of the nine youth, seven were currently involved in some form of youth development programme at the time of the interview. The programmes youth were or had been involved in ranged from CAYAD (Community Action on Youth and Drugs) services, multi-service agencies and alternative education establishments. An example of a multi-service agency is when a number of programmes such as YDPs, drug and alcohol counselling, and health, are situated within the one location, better enabling them to collaborate services. In most cases a young person's initial and constant contact will be with the youth programme which often has the funding 
and flexibility that allows for more informal and recreational activities through which youth workers have the opportunity to build rapport with the young person. In building rapport a youth worker is more able to learn the young person's needs and interests so that they can then coordinate help and services that will fit the unique needs of the individual. One youth participant explained how along with the efforts his youth workers were putting into helping to get him into a new school and back into his sport, they provided activities that kept him occupied:

$$
\begin{aligned}
& \text { "they just keep me busy instead of going out and doing heaps of } \\
& \text { stupid stuff... like the activities during the holidays, go fishing } \\
& \text { and stuff" - Elijah. }
\end{aligned}
$$

Alternative education programmes tend to have a multi-service function also as they offer education, counselling and rehabilitation services. The key difference is that as they are an alternative to school youth attend for the whole day, five days a week. As one young person explains,

"They keep me doing work all day... Correspondence: Maths, English and stuff" - Duncan.

Furthermore, the additional services such as counselling happen within the day's structure. Within each of the programmes youth were involved in participants identified having at least one youth worker or counsellor allocated to working with them on an individual level. Eight of the nine youth were or had been involved in alternative education at some point due to not attending mainstream high school either by choice or direction. The young person who had not been involved in alternative education was currently awaiting acceptance into a new school due to having been expelled from his previous one. 
Participants also identified having some form of involvement with government agencies such as the Police or Child Youth and Family (CYF). Seven of the nine mentioned having Police involvement at some stage, one of which was due to running away, the other six for more serious behaviours such as violence and disorder. Five spoke of having CYF services on board either previously or continually. Four of the nine youth acknowledged being subject to at least one Family Group Conference (FGC) while another three explained some form of group conference where professionals from sectors such as the Police and Ministry of Education came together with the youth and their family to address specific concerns and interventions.

Finally, with regards to specific behaviour concerns, five of the youth mentioned receiving some form of alcohol and drug counselling or intervention and three discussed receiving counselling for anger. Such counselling sessions were a result of referrals made between agencies, as well as counselling within multi-service programmes.

Sub-Research Question 2: To what extent has the young person experienced collaborative process through their involvement with youth development services in New Zealand? What was their experience?

Only one of the nine participants were able to identify what collaboration was when initially questioned. Once it had been explained to them, six of the youth were able to immediately identify some form of collaborative process they had benefitted from through youth services in New Zealand. By the end of the interviewing process it was apparent that eight of the nine had clearly received some form of collaborative intervention from youth related services. The collaborative processes that youth described generally fit into what Okamoto (2001) describes as case-level collaboration where professionals come together with the different services each has to offer to provide the support needed by the young person. This happened both within multi-service youth development programmes and across 
independent agencies such as CYFs, the Police and counselling services. Seven of the nine youth shared multiple examples of collaborative processes they had benefitted from. For all that were involved in a multi-service youth development program this was a form of collaboration they recognised quickly. Others noted ways that different programmes and services had worked with them both separately and collaboratively to support their different needs, for example, one young person explained how his youth worker worked alongside the Police and CYF to get him out of home and get him on the benefit:

"All three of them [worked] together to get my benefit" - Alex.

Youth were quick to identify the services that they felt had worked for them, some offering the information before being asked. These tended to be the services that took a more all-round holistic approach of not only providing youth workers, counselling, and educational support but making an effort to work alongside the family, keeping a good line of communication with parents and guardians. For all those who had been involved with a multi-service YDP this was their first recognition of collaboration in action, while for the others it was generally their youth workers from the various programmes they were involved in that they saw as carry out collaborative practices.

Agencies and workers that had been involved in making referrals but not maintained the same degree of contact did not stand out to the same degree for youth as having been part of any collaborative process. Such involvement was often an afterthought following further discussion and probing, as can be seen in my interview with Elijah, below. At this stage in the interview Elijah had already explained that he was involved in a youth development programme with two youth workers that worked alongside each other to help him but that they did not collaborate with anyone else:

Have you had any dealings with the Police? 
Ah yeah, last year.

But they haven't done any work alongside you or anything?

Oh they, I think they signed me up to [the youth development programme].

Did you have a particular youth aid officer that was working with you?

Oh yeah but I don't know his name.

Sweet as. Was it the youth aid officer that referred you to [the youth development programme]

Yeah

Choice. And have you ever seen him since?

Nah

\section{... later in the interview...}

Is there anything else [the youth workers] do in particular... like do they have one on one sessions with you?

Yeah

Is it counselling or is it...

Oh, I've got a counsellor, um, Drug and Alcohol

And is that through them as well or is it through someone else?

Through them

But it's a separate person, not [the youth workers]?

Nah, separate person

The YDP Elijah was involved in is a multi-service Police Youth Development Programme that is further supported by a trust. This example of youth requiring much 
probing before acknowledging the various services that had been or were currently working with them was just one of six, more than half of the participants. There could be a number of reasons for this - youth may not have seen those services as relevant, the question may have been unclear to them, or they may have so many services working with them that trying to remember everyone is too much. Whatever the reasons for the initial lack of recognition, it is my view that a young person that was involved in the planning process of their development programme would be more readily able to list the various people that were working with them and how they work alongside one another. I appreciate that understanding the ins and outs of collaboration is by no means the priority outcome for youth involved in services. However, the benefit of individuals being involved in the planning process of their development is that they would be more engaged and empowered for achieving positive change and growth (Guthrie \& Guthrie,1990; Okamoto, 2001; Mitra, 2004; Wyles, 2007; Beadle, 2009).

Having acknowledged the involvement of other less involved services youth generally continued to express a preference for the work provided by those who maintained regular contact as they felt they knew them better and that things were better explained to them by such people. Zach is an example of one young person who showed appreciation for the various services he had received but was most appreciative of the work his current youth worker was doing with him. His reasoning for this is best described through his statement below:

Just feels like I know her better than everybody else, like all my other counsellors and stuff I just go there don't even know them. - Zach

A common example of youth's despondence of some of the other services that were involved with them is illustrated by the five youth who had Child Youth and Family on board. After having the meaning of collaboration clarified to them and being asked whether 
they felt they had benefitted from collaborative processes in any of the services they had received only one offered up CYF as an immediate response but then explained that she did not feel she had benefitted from the work they carried out. With further questioning and probing throughout the interviews however, it became apparent in each of the five cases that CYF case managers assigned to the young person had made a number of referrals, assisted parents, attended FGCs and directed change in the young persons' lives that the youth generally felt they had benefited from. Here is an example of where collaboration is happening and services are making a difference but youth are not able to immediately recognise the positive outcomes. Perhaps youth involvement in the collaborative process would improve youth awareness as they take part in both planning and evaluation of the various interventions.

Family Group Conferences were another example of collaboration that was not initially recognised by youth as such. In most cases it was only once they had considered the role of CYF and/or Police in their services that FGCs were then raised. The Family Group Conference in New Zealand is in large part a result of the CYP\&F Act of 1989 which "required that family group conferences (FGCs), involving the extended family and community representatives as well as professionals, be used in decision-making in juvenile delinquency and in child protection cases" (Levine, 2000). When FGCs did come up, there was a generally negative feeling towards them. Following is one young person's response to how he found the FGC experience:

Annoying. Just everyone else is saying something, mum's there, she's saying something, you don't agree with it and then you talk back and nothing you say matters really. Waste of time. Alex

When another young person was asked if he felt in control at the FGC, he responded: 
Nah, didn't get to say much, oh anything. - Duncan

Others had similar experiences of feeling spoken at and not heard. Despite the generally negative experience youth had had, some were able to recognise some positive outcomes from the FGCs they attended such as referrals that were made following it and its effect in deterring behaviour. As Rongomai put it:

\section{I learnt not to get into trouble. - Rongomai}

In like-form to the FGCs, the three youth that had been involved in less formal group conferences involving family and professionals also took some time before acknowledging this collaborative process. These meetings however were not portrayed as negatively as the FGCs. While one youth explained his meetings were frustrating at times due to being nagged at, each felt that the meetings were generally good and explained results coming out of them such as being referred to a counsellor or youth development programme. The second of the three explained that it was an uncomfortable experience and that he did not want to listen but he put this down to his own attitude at the time and not anything that the adults could have done better. The third explained that it was a good experience because:

\section{They understood where I was coming from. - Jess}

The quote from Jess above spoke of the positive experience she had had of feeling understood in her meeting with a representative from the Ministry of Education, her principal, the deputy principle, her dean, the school counsellor and her parents following an incident that had happened at school. In order for the professionals to understand where Jess was coming from, there is an implication that she was given the opportunity to share in the meeting. Jess was the one exception to the findings outlined previously in this section in that she did feel she was able to contribute within the meeting but did not appreciate the work of the youth workers that were referred as a result of it. Her rationale for this can be seen in the following statement: 
I didn't really like talking to them coz they were different people that came into something that they don't even know about. Jess

When asked if there was anything in particular that they did to make her feel uncomfortable with them she further explained:

The way they spoke to me and... like the way they treated me like I was this bad person that didn't deserve to have like happiness. - Jess

In contrast to this, Jess felt really good about the work that her school counsellor had carried out because not only had the counsellor taken the time to get to know her, Jess was also able to get to know the counsellor as she shared her own background and experiences. In essence, the counsellor built a relationship of trust and understanding with Jess.

Jess's story is a good illustration of the common theme that arose within the discovery phase of the interviews as we discussed what is, and what has been. Relationships were key to youth's perspectives regarding successful and unsuccessful services. Generally, if the youth felt respected and heard by a particular worker or service then they felt it benefitted them and if not, they did not.

Further examples of how relationships of respect impacted the youths' perspectives can be seen through stories shared by Zach, Duncan, and Desire. It was highlighted earlier that Zach was most appreciative for the work that had been carried out by his current youth worker because he felt he knew her better than any of his other workers. In the 'dream' phase of the interview when considering possibilities of what could be Zach was explaining how he would like the collaborative process to run similarly to how it was with a previous youth worker he had had when the worker and his parents came together with him on a weekly basis. He felt that it could work much better this time having his preferred team on board, 
which instead included his current youth worker and his parents. Here is an excerpt of the conversation:

How did it go beforehand... with Steph?

It was alright. I used to get kinda shitty though coz they were always nagging at me telling me I can't do this and can't do that...

Sweet as, so who was involved then, Steph...

It was Steph and my mum and my dad come out

And you'd swear at them yeah?

Oh yeah, just when they'd tell me I'd done things wrong

Do you think if Lisa ran it it might be more laid back, more positive..?

Yeah

So with saying that, Sarah's approach to working with you is... generally she focuses on positive things or...

Yeah, Oh I like get to have my say with her. Not like before just them nagging, I actually get to say something.

Duncan explained very early in his interview that while he had had numerous agencies work with him his current youth development programme was the only one he felt had successfully rendered services that benefitted him through a collaborative approach. While he later acknowledged appreciation for other efforts that had been made, his strong initial stance can be best understood through the following accounts:

Is there a difference between your relationship with CYFs and here?

Yeah. Can talk to them better here. I've never really like[d] CYFs people.

What do you think the difference is that makes you wanna talk to them, or not wanna talk to CYF people? Is it the way that they treat you or is it just the fact that they're from CYF?

The way they treat me.

Can you give me any examples of how they make you feel? 
I had a FGC once and my social worker called me a alcoholic and a drug addict, and then I walked out.

Is this the person that's supposed to be advocating for you yeah?

$\mathrm{Mm}$.

And, the difference between the guys and girls here. What is it that they've done to make you feel good?

Umm, just like teacher Martin out there he teaches me like how to play guitar and stuff. They actually talk to you. - Duncan

In further discussing his experience with CYFs, Duncan explained:

I cried. Coz it was sorta true but she didn't need to say it like that.

For Desire, the respect was less about words and more about reliability:

Is there any difference to the way that the people at the FGC or CYFS dealt with you to the ways that the guys here and [the other] team work with you?

I think so, it's like um, I got more support from [mentor] and people here than from my social workers and stuff.

Yip, how would you define more support?

If I needed them they'd just come and see me but if it was CYFs it would take 2 or 3 weeks, a couple of months, just to come say hello. Something like that.

While rapport is something that as a youth worker I was always aware of and assumed most professionals involved with youth services accept plays an important role in providing successful services, just how much it impacted the youth perspective over other components of intervention was a refreshing reminder. It illustrates their desire to be treated like a normal person, an active participant in decisions pertaining to them. It is their life and they want to feel in control and respected. All showed an attitude of accepting they needed help from youth workers and others, they just did not always agree on the way the 'help' was being offered. The following quote sums up perfectly what each of the other youth seemed to be 
portraying. It comes from the oldest of the 9 participants who has moved on from youth services:

All they want is people to listen to them... If no-one listens to the youth then they're just gonna keep doing what they're doing. Just hear what they've got to say then ask them questions nicely, don't yell at them. Coz that's how I reckon you'll have a better relationship. - Tasha

With regards to people youth felt supported by in their development as a person, again it was those that showed them respect and allowed them a voice that they felt had and could continue to support them. Furthermore, youth tended to distinguish between those people that were there for them unconditionally, those who genuinely wanted to help them and respected them, those who made them want to be a better person and those who influenced them negatively through means such as peer pressure. Family was of particular importance to seven participants due to being there unconditionally, understanding, and being able to relate on a personal level - this was particularly said of older siblings as well as parents. Following are some examples of responses to questions around support:

Oh, I always listen to my sister, coz she's been there and done that. - Elijah

Um, like for me I like having support from my brother and stuff coz they're there to talk to whenever I need it and like if anything happens they're there. - Jess

My family, my dad and mum and that. And some of my mates that keep me out of trouble... stop me mixing with the wrong crowd like I used to... [it's] just good to know that I have them there when I can talk to them. Get whatever off my chest before I do something stupid that I'll regret the next day. - Alex 
It is not surprising that when youth were asked to consider their 'dream' collaborative team it was those with whom they felt well-supported and understood by that they wanted involved.

Sub-Research Question 3: If the youth could choose a team of people to work with them through their needs, who would they select?

When participants were given the opportunity to consider who they would like to be involved in their development during the 'dream' phase of the interviews, the uniqueness of each young person was revealed. While the relationship and respect factors were a common requirement amongst all of the youth, the other areas they felt they would like support in and how that support should be rendered varied. Seven of the nine youth felt that some form of education, whether it be getting back into school or gaining qualifications/work experience elsewhere, was important and that support was needed to achieve this. About half of the youth acknowledged that it was important to have friends around them with one wishing to have her friends as part of her support team, another naming one friend in particular that he wanted on board, and a third wanting his girlfriend involved. Sport was particularly important to two of the young people, with one explaining that:

\section{It keeps my mind off all the bad things that are happening. - Jess}

Five of the youth mentioned having received some form of drug and alcohol intervention that had been helpful, with most wanting continued support in this area. Tasha had not received such support when she was struggling in this area as a 15 year old and wishes she had. Financial support was of particular importance to three of the four who had moved out of their parents or guardians care. While two had received help in gaining the benefit, the third shared his desire for support in applying for it. 
Having considered those areas that the youth felt were important to them, they were asked to decide who they felt could come together as a collaborative team to achieve this. After naming those persons they required, they were asked how they thought the team would work best for them - coming together for regular meetings, or meeting with the young person separately. As no one youth had the same response I will introduce each youth and their dream individually.

Duncan, 14 years old, would like to have his current YDP, another local youth service, 'the lady' that did a twenty week in-home programme with him and his parents to help with his drug, alcohol and attitude concerns, the Maori wardens, and his aunty on board. He feels the best way this group could collaborate to help him is by coming together once every two months as he does not feel he would go to them by himself. Outside of this he feels it would be important for him to have one worker that met with him on a more regular basis.

Desire, 14 years old, would also like to have his current YDP, 'Rick' from a local education and training programme, his parents, his girlfriend, and all the staff from a 24-hour facility he was previously with for 10 months. He feels that it would work best if they all came together and feels that he should take control of the running of the meetings. When asked what this would mean to him, he responded:

Happy. Glad that I got them all together. And love the fact that they're there. - Desire

Jasmine, 14 years old, is content to continue with the current YDP she is with and not change the way they work in any way. She does not feel the need to include family or any other outsiders. An explanation for this might be summed up through her feelings regarding what being involved in a YDP has meant for her:

Um, like life, got a better outlook on things, where I wanna go... I didn't wanna do anything except stay home. - Jasmine 
Zach, 15 years old, would like to have his youth worker and his parents come together with him on a weekly basis. He feels that it would help both him and his parents.

Alex, 17 years old, would like three of his counsellors/youth workers that have helped him with anger and violence concerns, his mum and dad and his friend to be a part of his collaborative team of support. He does not feel that they need to come together as a group, he would prefer to be able to go to them separately and feels that he would do so.

Rongomai, 18 years old, would like her alternative education tutor, her youth worker, and her drug and alcohol counsellor to be a part of her support team but also feels that she would prefer to just go to each of them separately. This team of support is important to Rongomai as:

It means that I can go and ask people and know that they'll help me and I can rely on them. - Rongomai

Jess, 16 years old, would like her brother, school counsellor and her friends to make up her team of support and would prefer to go to them when she feels like it. She explains how it feels to know those people are there for her:

\section{Makes me feel stronger as a person coz I know that people are there for me and aren't gonna judge me for things that have happened. And yeah, they're just there if I need help. - Jess}

Tasha, 20 years old, reflected on what she feels could have worked better for her when she was around 15 years old and feels that it would have been good to have two of the youth workers from a CAYAD programme she attended work with her on a more personal level, along with her parents and her older sister. She too feels that it would work better for her to see them separately, the workers as one, her parents as one, and her sister.

Elijah's, 16 years old, preferred team includes his dad, his older sister, his youth workers and his drug and alcohol counsellor. They are currently working collaboratively but 
not all coming together as one at any time and he is not sure if he would change it. So far, he feels that the way things are working has been successful:

Yeah I've made a... since last year I've made a big difference... My attitude; not getting in trouble with the Police; haven't gone into the cells. - Elijah

Seven of the nine youth made a point of involving at least one member of their family in the collaborative team. The other 2 participants mentioned the importance or significance of family members at other points in the interview. This finding highlights the value to which the young people put on family, even despite the fact that at some stage of their life each of them had been removed or elected to live away from their parents. This is an important point to keep in mind when looking at who should be involved in the collaborative team.

It is interesting to note that within the above dreams the younger youth tended to prefer the idea of their support team coming together, while the older youth generally wanted to be able to go to their support people separately. This is highlighted further in excerpts of the interviews below, note the correlation between the different responses and age:

Conversation \#1 - Duncan, Male, 14yrs:

Would it work better for you to just go to these people as you felt, when you felt you needed it or they come together as a group to help you?

A group.

Come together as a group?

Mm (yes)

Any reason why?

Coz I won't just go to them.

Yip. How regularly do you think they'd come together?

Umm, once every two months or something. 
Choice. And would it be important for you to be able to go to one person more regularly than that or do you think that would be sufficient?

Yeah, that would be alright.

That would be alright just like that?

Oh, having someone else.

Ok, having one person that you could always go to?

Yeah.

Conversation \#2 - Desire, Male, 14yrs:

Cool. And if you had all those people how do you imagine that it would work to have them working as a team? Would you just go to them when you needed to or would you have them come together as for meetings.

I'd have them come together and have meetings.

Yip, any reason why you'd prefer it that way?

So my family can get together. Have a good conversation and korero.

It's important for you to have your family there?

Yeah

Any reason why?

Coz they've always been there for me.

So as they come together, how would that run? Would you have one person leading the forum or would you take control?

Yeah I think I'd take control. - Desire, 14yrs

Conversation \#3 - Alex, male, 17yrs:

Okay, going back to that group, if you could make up a team of people that would help you, how would you, would you prefer to just go to them when you wanna go to them....

Yip!

Rather than having everyone come together?

Yeah! 
Okay. Do you feel like you would go to them?

Yeah yeah, I would definitely.

Have you ever been in a situation where they've all come together...

Yip. Family Group Conference and that sorta thing.

How did you find that?

Ah, annoying, just everyone else is saying something, mum's there, she's saying something. You don't agree with it and then you talk back and nothing you say matters really. Waste of time.

If you could make something like an FGC happen but everyone be in support of you and actually listening to what you have to say, would that work?

It could help, it could work. Depends on what the situation is, depends on why I'm there, so many different things.

So just in the way of being able to go to those people that you feel you could go to, are you quite happy that you're able to do that now?

Yip.

Yeah? And you wouldn't need to make it any more formal than it already is?

Nah.

And what does it mean to know that you have those people there for you?

It's just good to know you've got support.

Conversation \#4 - Rongomai, Female, 18yrs:

How would you imagine them coming together to help you? ...Would you have a meeting kind of like an FGC but more on your own terms or would you just go to them when you wanted to go to them?

Yeah, when I need help and stuff. Yeah.

Would you go to them separately or together?

Separately. 
The different preferences amongst age groups may be due to an increase in independence as one gets older, taking more responsibility on and choosing to be accountable to one's self rather than others.

While all of the background logistics of how their dream team could be made possible were not discussed in depth, most felt content that by talking to their youth workers they could make their dream happen. As was highlighted in some of their quotes, what was really important to the young people was the knowledge that they had people around them who genuinely cared for them and wanted to know and support them. Knowing they had at least one person they could trust and depend upon gave them the confidence that they could pursue their dream with the support of that person.

The difference between a young person knowing they have these supports and not knowing they do can be seen through Tasha's story as she reflects back to a time when her older sister had moved out of home and she felt that she had no-one to go to anymore:

...it was like now that she's gone now who do I have to talk to and stuff like that. And that's what kind of, I don't blame her or anything but that's when I went astray coz I didn't have an idol to look up to. But I do, I never thought about it then, I just thought you know, she's gone, never mind, do what I gotta do, but it never worked so...

Yip. So besides [your sister], like you say you didn't think you had other people around you anymore but you did, who are some of those people

I had her but it just never, came to mind that she was there. Then my brother moving and I was like oh I have no-one blah blah blah. Then you come to think of it as you get older and you think about how they were there and you just never asked them. And that's how I was so, I just had to ask but I was too scared to ask. 
Do you think that's something common amongst most youth?

Yeah, most youth.

... So back then I guess you didn't feel like you had the resources to be able to...

Yeah nah, I didn't think I had anything at all.

Whereas now you look back...

And yeah, I had everything.

But you didn't know it was there.

Or else I was just blocking it out, and I would think what's the point, no-one's gonna listen.

Tasha's story draws attention to the idea that while youth often do have the supports around them that they so clearly desire, a lack of communication and understanding from both parties may be all that is missing. In going back to the concerns that have been raised throughout this chapter about not feeling respected or heard by certain people or services it seems that this gap in communication and understanding between youth and the adults around them is all too common. The question is whether improved collaborative processes can help to address this concern or whether it is a separate issue altogether. Perhaps first summarising the findings thus far may help to answer this question.

Main Research Question: What are New Zealand's youth's experiences of collaboration when involved with youth development services?

Disregarding the concerns around relationships, the overall consensus for the youth participants was that professionals are working together to provide services that benefit young people. The extent that collaboration for youth development is happening can be appreciated through considering the various definitions of collaboration discussed in the 
literature review. The functioning of collaborative processes seemed very much dependent on the region the young person came from which suggests that the regional co-ordination as discussed in the 'Mosaics' document published by the Ministry of Social Development (2003) is happening in at least some areas of New Zealand. The 'Mosaics' document also outlined operational level collaboration which is essentially the same concept as case-level collaboration explained by Okamoto (2001) where professionals come together either within multi-service agencies or at an inter-agency level to provide services specific to the needs of a young person. The examples discussed of youth not only having a youth worker assigned to them but additionally receiving forms of counselling and education services implies that this form of collaboration is also in action. Organisations that were involved with youth included government, non-government, and combination-funded agencies - such as Police Youth Projects which have both an element of Police resource and funding, along with additional support and funding provided by a trust.

Youth participants judged the effectiveness of collaborative process surrounding their development both by what they had achieved through interventions and how they felt when being dealt with by the various agencies involved. In regards to what had been achieved, the seven who were receiving services at the time of the interview were content that not only did they have a better outlook on life and have goals that they wanted to accomplish, they were content that with continued support from those who were already around them they could be successful in moving forward. Of the two that were not under any current service, one was grateful she had been involved with one positive service in the past that had given her a little more direction but wished for better services to be rendered to those younger than herself. The second felt positive that with the support she had previously received from one worker in particular and the continued support of her family she too was equipped to progress more positively than she previously had. It would seem that while most of the youth were not satisfied with all of the work that had been or was being carried out with them, each had had 
at least one agency or professional that had made enough of an impact to make them still feel good about their development within the programme.

Services or professionals that youth did not feel satisfied with were generally those that seemed to lack rapport and a display of genuine care to the young person. While the young persons' accounts may be very one-sided, professionals are there to work with youth and should therefore be trying to meet the young person at their level, making a considerable effort to show them the same degree of respect they would to adult cliental or colleagues, perhaps more. Participants' explanations of how they felt when they were labelled an alcoholic or made to feel like a bad person shows their sensitivity to what they consider a personal attack, a reminder that while they may put on a tough front and appear not to care, they really do. Such sensitivities may be something that some professionals are not aware of, or understand differently, a knowledge that could perhaps make a big difference to their interactions with youth in the future to ensure the young person receives services more willingly.

One section of the literature review in Chapter 3 discussed who should be involved in the collaborative process and it was suggested that, along with professionals, youth and their families should be central to collaborative processes. One of the key differences between the services youth felt positive about and those they did not was the degree to which they felt heard or able to contribute. Family group conferences are a perfect opportunity to allow for such a well-rounded collaborative approach and yet this was one of the most negative experiences that each of those who had been involved in a family group conference had had due to feeling attacked and not able to contribute. In contrast, Jess's experience of attending a similar kind of meeting but actually being able to contribute and feel she was understood meant that this was a really positive experience for her. Those programmes and workers that are involving youths' families, meeting youth at their level, treating them with care and respect, and working with them as opposed to working on them (like a project) are the ones 
that youth see to be beneficial. Furthermore, it should be noted that during the design and destiny stages of the interviews, youth displayed feelings of empowerment as they realised the role they themselves play in their development within the youth services. Some left the interview determining that they could discuss their ideas with a youth worker and others acknowledged feeling able to implement their possibilities themselves. These findings support the importance of not only youth-centred but youth-involved collaborative processes.

The findings above address my earlier question regarding whether the gap in communication and understanding between youth and the adults around them could be improved through better collaborative processes. The findings suggest that when collaborative processes involve youth and family youth will feel more positive about experiences and the professionals involved. I believe that if the youth participants were more involved in the planning processes of their interventions and understood why certain referrals were being made and asked how they felt about it much of the confusion and lack of appreciation around certain services that came through during the interviews would be overcome. Seeing the feelings of empowerment that youth displayed when asked who they felt should be on board with them and how they felt it could work gave me a glimpse into what could be if improvements were to be made in this area. (In essence this was the beginnings of the destiny stage in action, where the dreams begin to become reality as participants see that it really is possible). By being involved in the planning process and being asked how they feel or what they feel they need youth would not only feel respected and appreciative of what is being offered, they could feel so much more empowered and in control of their own futures.

In summary, this chapter has addressed the youth perspective on collaboration within youth services in New Zealand. It has highlighted that there are a number of services available and being used by individuals according to their needs. Each participant had a different experience of youth services that they had been involved with. Most had at least one 
example of both a positive and a negative experience within the services and were able to identify the differences between each. Often, the key difference related to how they felt professionals treated them. The findings have highlighted that while participants confirmed that collaboration for youth development is happening, it could be greatly improved if greater consideration of the young person was taken. The following chapter will discuss these findings further in relation to the literature and consider how the needed improvements could be implemented. 


\section{Chapter 6 Discussion: Potential for Improvement}

I am more than a file. I am a person. I have feelings and am entitled to respect. Please don't only see the problems, see the potential. - Lay, 2000, p.68

Referring to himself as being under Permanent Government Ownership Jonathan Lay (2000) has been under Canadian youth services for all of his teenage years. Having given a speech at a conference for Canadian youth workers, the Reclaiming Children and Youth journal were so moved they invited him to write an article expanding on his previous comments. The above quote comes from his opening address. In this simple statement, Lay articulates a key theme of the findings from the New Zealand youth perspective above. For the purpose of this study, Lay's statement highlights two important points. First, New Zealand youth are not alone in their concerns for wanting to be heard, understood, and respected when being dealt with within the youth sector. Second, practitioners and academics are hearing the call. It is my hope that the more real accounts from youth such as Lay and our own that are voiced the greater the momentum for change will be.

The purpose of this chapter is to embrace the findings and narratives of our youth and attempt to better understand them for the purpose of finding ways to address the concerns raised. To achieve this I will explore links to the literature and ideas discussed within the first half of the thesis. The youth perspective has highlighted that while collaboration is happening within youth development services in New Zealand it is not reaching its full potential as aspects of it fail to appreciate what is entailed in being youth-centred. This concern will guide the discussion within this chapter through first addressing the need for transparency to youth and allowing for the youth voice to be heard. This will include a look at the possible impact of bureaucratic processes that may be impeding on the potential for youth to be more 
centrally involved. The second half of the discussion will be around possible measures for overcoming these concerns.

Beals (2006) noted that discussions of improved holistic practice are not always matched by delivery. Findings from the youth perspective are evidence that while the collaborative approach is being implemented for youth services in New Zealand, delivery is not yet such that young people are feeling sufficiently supported and heard. Agencies seem to have strong local networks and are working together to ensure the required services are getting to the right youth, however, due to youth not always being party to collaborative processes the opportunity for empowering them for self-reliance and resilience in the future is being missed. In failing to involve young people in processes, relationships of trust and respect are not being built and so good work that is being carried out is being overlooked by feelings of contempt.

'Collaboration' was defined in Chapter 2 as "the extent to which professionals, families, and the young person work with one another to plan and carry out a youth-centred process of intervention for positive change and growth" (p.20). Justification for this definition can be found in the literature review within the works of Guthrie \& Guthrie (1990), Okamoto (2001), Mitra (2004), Wyles (2007), and Beadle (2009). Each reinforces the need for good, youth-centred collaboration to involve not only the family but the young person as well in planning and carrying out interventions. Some of the reasons behind the call for inclusion are that it creates an environment of shared learning and respect, it empowers the young person through giving them control over their life and future, and it ensures greater feelings of agency and belonging. The findings presented in the previous chapter have highlighted that while some programmes and services are ensuring youth feel informed and heard with regard to the work that is being carried out for them others are not. Eight out of the nine youth interviewed had at some stage had at least one negative experience with youth services in which they had felt let down by. 
While it is good to know that the call for collaboration is being heeded within the youth sector, the need for improved youth involvement must be addressed. Sanders and Munford (2005) acknowledge this negligence in services as they discuss the irony that while social work in New Zealand is focussed on improving outcomes for children and young people within the family, the children and young people themselves are not being consulted. They explain that disregard for the young person's inclusion will likely result in resistance due to not feeling genuinely respected. As was pointed out by one of the participants, if youth do not feel heard and respected they are not going to care too much for the services on offer. Lay (2000) reinforces this feeling as he explains his disinterest in opening up and sharing his story with a person he does not feel any connection to. Practitioners must realise that expertise and an education are not enough to address the needs of their clients. Be they young or old clients are key to creating their own change (Laursen, 2000; Gilligan, 2004; Sanders \& Munford, 2005). Gilligan explains that for some it will require concerted effort to accept that as a youth worker it is not all about providing fix-it interventions but rather, it is about helping youth help themselves. This is only possible by working in partnership with the young person, not directing them.

Camino (2000) discussed the importance of partnerships when she identified the enhanced mutual respect and understanding that results from adults meeting youth on equal grounds. It seems logical that human beings find it much easier to respect those who respect them. By inviting youth to share and be involved in planning and carrying out efforts for their own growth and development, professionals are essentially acknowledging that while they may have the expertise and resources to help, the young person's future is in their own hands and therefore what they have to say and feel is of significance. Once youth feel heard, recognised, understood and affirmed by an adult wanting to help they are less likely to engage in power-struggles and put up resistance (Laursen, 2000; Gilligan, 2004). 
An example of the importance of building mutual respect can be found in my own experience with carrying out this study. On initially making contact with different agencies and networks to gain referrals for the study one of the questions I was asked related to how I was going to get such youth to talk. The implication being that they were a bit rough and tough and might walk all over me. Having explained my interest and reasoning for the research I wished to carry out to each of the youth participants and highlighting my desire to hear and represent what they had to say I found all of them more than willing and respectful. Each was welcoming of me into their space, well-mannered, and very keen to share their stories and feelings regarding their experiences. One of the youth workers I dealt with explained the excitement her youth conveyed at being asked for their opinions. In essence, they felt that I respected and wanted to learn from them and so they were willing to show respect and share with me.

The above example introduces a further fundamental to the need for involving the young person. While the idea of giving respect to receive respect is nice and will certainly help, the respect must be genuine (Schnellbacher \& Leijssen, 2009). As Lay (2000) points out, 'I can tell if a person really cares and wants to help or is just doing a job for the money" (p. 69). In the literature, the concept of genuineness is explained as authenticity (Laursen, 2000; Sanders \& Munford, 2005). Laursen suggests that an authentic relationship may be more important than any other treatment or intervening technique a practitioner has to offer. He justifies this suggestion by explaining that authentic relationships enable belonging and connectedness which allows adults to set boundaries in meaningful and caring ways that youth will respond to. He explains that this is so because when a practitioner has an authentic relationship with the young person he or she will understand where the young person is coming from and what they see as the problem and so will fit his or her practice around that knowledge, continually communicating along the way. 
Part of what Laursen (2000) is touching on is the willingness of the practitioner to learn from the client before making his or her own conclusions and recommendations. In my own example above I did not simply put a smile on my face and show the youth respect. I explained to them my motive, my desire to hear what they had to say so that perhaps my findings would help to ensure that youth services in the future were better suited to them. It was the idea that I, and potentially the readers of my research, had something to learn from them. Sanders \& Munford (2005) bring this notion of professionals and academics learning from clients back to concepts of collaboration. They explain that true collaboration means that along with working and learning together as professionals, practitioners must also be willing to work with and learn from their clients. They explain that in doing so practitioners will ensure themselves life-long learning experiences as they come to understand the repertoire of knowledge and skills found in those who have lived under particularly difficult and demanding circumstances. Laursen (2000) reinforces the need for collaborative teams to involve the young person and their family as he explains that, along with the opportunity it provides for professionals to learn of their clients' strengths, the shared learning means it can further ensure that clients are less-dependent on professionals in the future as they adopt new ways of approaching difficult situations.

Laursen (2000) noted that including family in the collaborative process could further help professionals learn of their client's strengths and background. As with the importance of the youth voice, the importance of family involvement in the collaborative process has been discussed throughout this thesis. Benefits of including family that were raised in the literature review included: the role they play in giving support (Bandura, 1964), instilling values (Coleman, 1978), increasing feelings of belonging (Bishop, 2005), improving social capital (White \& Wehlage, 1995), enhancing cultural competency (Wyles, 2007; Hynds, 2008) and strengthening parent-child relationships (Steinberg \& Duncan, 2002). Findings in the youth perspective further reinforce the role family plays as participants shared the important place 
in which they hold parents and older siblings for giving support and being there unconditionally.

The framework upon which much of the recommendations around collaboration and authentic relationships are based upon is that of the increasingly popular strengths-based approach used within youth and social work sectors. Discussed to a degree within the Appreciative Inquiry sections of this thesis, strengths-based practice involves a move away from focussing on client deficits and problems to instead focussing on their competence and resourcefulness to being able to overcome the obstacles they are met with in life (Laursen, 2000; Sanders \& Munford, 2005). Furthermore, Sanders \& Munford explain that it allows greater opportunity for youth involvement and focuses on forward movement or development as opposed to being held back by too much focus on the past. Gilligan (2004) shares the experience of one practitioner who put the concept of seeing clients for what they have to offer into action: "The more I strive (and, sometimes, struggle) to see my clients as competent and successful so the more they tend to demonstrate these characteristics (and, at the same time, the more I simply don't notice their deficits or pathology)" (p. 97).

The need for strengths-based practice can be further appreciated through the explanation of Fattore et al. (2009) that policies and services for young people focus too much on what we don't want for youth instead of what we do. This idea also came out of the findings as youth discussed the negative impact of professionals and family members focussing only on the bad things they had done.

Critiques of the strengths based-approach express concerns that the practice may ignore or deny the problems for which people are coming to the attention of services in the first place. Strengths-based approaches do not ignore problems but rather they identify them and allow questions such as what can be done better or what can be learnt from them. Laursen (2000) further assures that this approach strives to discover the person's strengths so that they may then be used in addressing the problems or deficits of concern. Sanders \& 
Munford (2005) explain this as looking to the young person and their family as holding critical resources that will assist in the intervention effort. Mitra (2004) observes this argument by observing that by not enabling youth to be heard professionals run the risk of missing key information and insights that only youth can offer. She affirms that no matter how experienced and well-trained one might be, or how reliable ones source of referral might be, the young person's thoughts and feelings are essential to ensuring interventions will best meet their needs. In summary, Lay (2000) states, "I am the best resource you have to know and understand what is going on inside of me" (p. 69).

Further to their argument for the strengths-based approach, Sanders \& Munford (2005) explain that the authenticity required for such practice ensures that professionals are better equipped to deal with the hard facts as it involves honesty and an ability to communicate when things are going well or going badly. This means that while such professionals will still be required to make the hard calls and referrals that may not always be conducive to clients' desires, an authentic relationship will enable them to do this while maintaining openness and trust. The value of this may be appreciated when considering that young people within the system may have learnt over time through certain experiences that adults are unreliable (Sanders \& Munford, 2005). An experience from Desire gave evidence of such feelings when he expressed being let down due to not having his request for seeing a family member fulfilled following an FGC. While there may have not been any promise that all of his requests within the FGC would be met, his feelings of being let down when they were not illustrates a lack of understanding on his part, perhaps due to poor communication and explanation, that they would be. With their own findings showing that young people hold commitment and respect in high regard for ensuring successful outcomes, Sanders \& Munford suggest that workers need to be more committed to working long-term with their clients to better nurture trustworthiness and resilience. Gilligan (2004) further reinforces that experiences of alienation and disillusion from mainstream services highlight the importance 
of building trusting relationships with young people. He explains that by creating more secure attachments a young person will feel a greater sense of belonging within his or her system of support which is a necessity for enhancing the resilience that results in positive adaptation when met with further adversity.

The notion of developing feelings of belonging was touched on in an earlier chapter when I explained how Mitra (2004) found that when youth were given the opportunity to voice themselves they developed increased agency, belonging and competence. Mitra explains these three assets as comprising the $\mathrm{ABCs}$ of youth development that research in the fields of psychology and youth development have identified are needed for success in school and life overall. Sanders \& Munford (2005) further address such assets as they explain that a child-centred framework both emphasises and employs the agency and capacity of all, clients and professionals alike, for approaching positive change. The importance of these assets for building the resiliency that Gilligan (2004) spoke of should alone be enough of a reason to motivate professionals into promoting youth voice within collaborative processes. The more resilience a young person becomes through enhanced agency, belonging and competence, the less they will rely on services and the expenditure of resources in the future. While this section has discussed why the youth voice is so important for collaboration the following section will address some of the obstacles that may be holding it back.

\section{The 'Bureaucratic Effect'}

Obstacles to effective collaboration can be seen within both the literature review (Guthrie \& Guthrie, 1990; Weist et al., 2001; Beadle, 2009) and findings chapters of this thesis. When examined carefully it becomes apparent that the majority of obstacles come under the umbrella of bureaucracy. For this reason I have coined the term 'bureaucratic effect'. The word bureaucracy refers to organisational structures, procedures and protocols put in place to manage activity. Unfortunately, it seems that in managing activity with little 
flexibility organisations are limiting their staff from achieving effective youth-centred outcomes.

Examples of bureaucratic interference discussed in the literature review included the use of definitions, jargon, labelling, and agendas (Guthrie \& Guthrie, 1990; Walker, 2007; Beadle, 2009). Further examples were highlighted in the findings chapter when youth shared stories of the negative experiences they had with certain services or meetings. Such experiences included: Being called an alcoholic and drug addict by a case-worker within an FGC; drug and alcohol assessments carried out by CYF that made a young person feel uncomfortable; drug and alcohol counsellor telling a young person not to do this and not to do that; FGC not meeting a young person's request to see a family member when they were in town; CYF making a young person do stuff she did not want to do; the FGC process not allowing for the young person to have their say; and, Youth workers, Police, and other practitioners not building relationships - just making judgements or referrals and moving on. In the above examples we see bureaucracy presenting itself in the form of labelling, protocol, dictatorship, processes and procedure. For services that are essentially aimed at human (in this case youth) development, there seems to be very little focus on the human.

The 'bureaucratic effect' is the notion that services and organisations are too concerned with policy, paper work, and check-lists and not concerned enough with the young person and their development. Guthrie \& Guthrie (1990) advised that letting go of bureaucracy and organisational musts is crucial for ensuring child-centred initiatives as it will allow for the child's needs to take precedence over processes. Unfortunately, this maybe much easier to state in theory than to carry out in practice.

In looking again at the experiences the youth shared above it can be seen that the majority of them involved one or more government agencies who relied heavily on following the book as directed by policy. Child, Youth and Family come under the Ministry of Social Development and have clear procedures in place for the purpose of both ensuring 'best- 
practice' and holding staff accountable when things may go pear-shaped. Similarly, the Police, another Government department, have protocols they must follow to ensure consistency and accountability to both the crown and the people of New Zealand. For both of these departments media scrutiny is common. If structures are not in place to manage activity then it becomes harder to deal with complaints and criticisms that may arise. In fact, I would argue that almost every school and social service agency relies on some form of bureaucracy to ensure accountability and best-practice whether for specific activities or general day to day business. This may come in the form of a code of ethics, procedures for taking children out of school, and so on.

How can bureaucracy be done away with when it has its place? Is there a difference between procedures for ensuring safety and accountability and creating systems for the sake of systems? I would argue yes, and so to the first question I would say there is a place for a degree of bureaucracy in every organisation. The difference between government departments such as CYF and the Police versus community based organisations is that they are regulated by government policy and legislation which is often highly directive and structured leaving little room for flexibility to fit the service to the person or community. While the intention is to ensure best-practice, what best practice actually is can be highly debatable and in politics is often decided by whoever has the most power at the time. An example of this can be found in the debate over the national standards in reading, writing, and mathematics that were introduced by the Minister of Education mid-2010 (New Zealand Press Association, 2011). On one side, the National Government has argued that due to children not meeting current learning expectations in numeracy and literacy a set of standards are to be implemented along with a checklist for how this is to be achieved. On the other side, teachers and parents argue that a one-size-fits-all approach is not the answer (Clark, 2010). This point highlights a key difficulty for government when approaching the hard issues that affect such high and diverse proportions of the population such as education and social 
development. While the need for change is clear and people want to see that something is being done to address concerns there is often no quick fix answer that will work for the entire population, yet we continue to see the checklist approach rolled out.

One advantage of the "checklist approach", a term inspired by the current national standards debate, is that in areas of high demand such as education, social development, and policing, it means that a practitioner can go along to an appointment (or a lesson, or a scene), carry out the required actions, tick them off and then move on to the next task in their busy and demanding day. A possible disadvantage is that the lesson may go over the heads of half the classroom. Another possible disadvantage is that a young person being taken in for stealing may want someone to talk to about an abusive situation at home. The disadvantage, as we have heard, is that a young person may feel put down and disrespected after having been dragged through a meeting that labels them by all their faults by the person who is supposed to be their advocate that they in actual fact barely know. The checklist approach does not address the unique needs of the people that a service is supposed to serve because it does not allow for the time and rapport-building opportunity that it is required for doing so. Similar to the notion of 'red tape', the checklist approach refers to the view that bureaucratic procedures are often seen to be more of a distraction from making 'real' progress than of any long term worth.

The check-list approach does not apply to frontline professionals only. The following example explains the possibility that it is carried through from a checklist approach to policy making. FGCs came up a lot within the negative experiences discussed above. As was outlined earlier, FGCs are the result of the CYP\&F Act, 1989, which requires that they be used for addressing issues of "juvenile delinquency and child protection" (Levine, 2000). Both Levine and Conolly (2006) describe the innovation FGCs have brought to a previously pathological and discriminative system by empowering families (including extended family) to play a key role in the decision making process. Despite Levine pointing out how the law 
"fulfils New Zealand's obligation as a signatory to the UN Convention on the Rights of Children to provide the opportunity for children and families to participate in decisions that affect them" (italics added), both authors seem to focus solely on the benefits FGCs have on the family. Barely discussed in either of the evaluations of FGCs is the young person's place within the process. The impression of a checklist approach to policy making comes from this idea that the key concerns seem to be that the Act is culturally respectful in taking on a Maori model of justice and that family's play a key role in the decision making process. While FGCs tick both of the above boxes the concerns raised by the participants of this study imply that it is lacking real effectiveness in carrying out its purpose of addressing child protection and youth justice issues. Perhaps there is an assumption that the case-worker or family members truly understand what the young person wants and needs, or that the young person feels confident and articulate enough to share their thoughts and feelings. No doubt there are those that have had positive experiences using the process, however as the findings are overwhelmingly to the contrary there is a clear need for improvements to be made. The closest either Levine or Conolly got to this concern is when addresses the power dynamics of the family consult period. This is when the family is left alone for a period to make a decision regarding the young person's well-being or restitution. Conolly discusses the concern that some Family Group Coordinators have regarding one person in the family using their power status to guide the family's course of action.

The above examples highlight the negative side of bureaucracy that Guthrie \& Guthrie (1990) suggest needs to be done away with due to their interfering with ensuring initiatives that put the person before the process. If every FGC had the young person of concern at the forefront of their priority list, and similarly every social worker, teacher and Police officer, then perhaps there might be less negative experiences shared by youth regarding their experiences. This is not to say that such professionals are not concerned for 
the young person, rather that the systems under which they work limit their opportunities to be so much more effective and influential.

Just as can be seen in the debate in New Zealand around the education national standards, oftentimes front-line staff are very aware of the areas in which they could improve should the system allow them the flexibility of doing so. This is a frustration that I am all too familiar with through my own experiences as a youth worker and that has been discussed in the literature by the likes of Gilligan (2004) and Beadle (2009). While Gilligan explains how bureaucratic processes can cause gaps between management and frontline staff, Beadle highlights the need for involving frontline staff in research and discussions that guide the decision-making processes at a higher level.

With the challenges of the highly stressful and demanding environments such professionals are working under and the complexities surrounding bureaucratic processes, a solution for addressing this concern cannot be suggested simply through a study at this level by a single person. In considering this study as a starting point, I wish to discuss possibilities through which positive and informed changes might be made that will affect youth services within New Zealand as a whole.

I propose that Appreciative Inquiry would be an effective framework under-which to positive and informed changes might be carried out. With successful outcomes of positive change in schools, youth, and community development programmes in the United States it is an established model that has much applicability for a New Zealand context (Hammond \& Royal, 2001). It will allow for youth voice, along with frontline workers, managers, community leaders, policy-makers and other government officials to come together and address such complexities in a positive, forward-thinking manner that will create change for improved outcomes that will affect professionals and clientele alike. Furthermore, due to its use of socio-rationalist theory, initiatives that may result from the process will be flexible 
enough to appreciate the constant changes within society that affect youth and therefore what is needed within youth services at any given time (Bushe \& Coetzer, 1995).

Beginning with the discovery phase each participant has the opportunity to share their story of what collaboration within the youth service sector has meant for them. The expectation that this process be appreciative will help to ensure that all those who have come together to establish positive change will remain on good terms for working together as they move through the 4-D cycle and that the forum does not get caught up in the seemingly never ending realm of problem-solving. Moving onto the second phase the collective can begin to dream of what more they might envision the collaborative process to be. Here, they might discuss a process that can be undertaken without interferences of bureaucratic agendas, time constraints, and limiting definitions. As the group begins to realize what could be possible they will enter the design phase and craft "possibility propositions" (Cooperrider \& Whitney, 2005) of how this might come about. Finally, having a unified vision of possibilities the destiny stage can be activated to allow for the momentum that has been established to take off and bring about the desired changes. This will not be a matter of the government then acknowledging having heard the call and taking action themselves but instead, through continued learning, sharing, and experiences of empowerment, each will take action in the various capacities that they can to reduce further unnecessary bureaucratic interferences in the future.

As much time and effort would be required to make the above happen, I suggest a couple of steps that practitioners can take in the meantime to ensure that they are doing their part in putting the young person first. It is hoped that taking these steps will help to reduce the number of negative experiences that young people have with youth services in New Zealand. 


\section{Strengthening Youth Voice and Disposing of Labels}

The two over-arching concerns that youth raised in their interviews were that of not being heard and treated with respect, and that of being labelled or treated as a problem. While time may be of the essence to workers within the youth service sector there is no reason why these concerns cannot be addressed immediately.

The concern of not being heard and not being treated with respect comes under the umbrella of 'youth voice'. The importance of youth voice has been discussed in depth both in the literature review and earlier within this chapter of the thesis. How can a youth voice be achieved? I appreciate that at this point in time in 2011 professionals within under-resourced and over-worked government departments may not be able to find the time to build the kind of rapport they would like to with each young person within their heavy case-load. However, the stories shared by Lay (2000) and within the youth perspective highlight some simple ways for ensuring that youth feel they have a voice regarding initiatives relating to them. Lay outlined clearly the difference between the good experiences he had had within the services he had received under youth services and the bad experiences:

The good parts have been some of the caring, trusting, and supportive people I have come in contact with. The bad parts are when people don't listen or trust me. Sometimes people disregard my say in decisions affecting my life. One of my social workers tried to run my entire life. (Lay, 2000, p. 69.)

This statement is very much in line with those shared above by youth in New Zealand. Putting all the complex issues of time, case-loads, and processes aside simply looking at this statement does make the short-term solution appear very straight-forward - show that you care, trust in the young person's potential for change (Sanders \& Munford, 2005), and support them through that change by helping them, not directing them, to achieve their goals. 
While these three steps seem self-explanatory, I will provide an elaboration on each point briefly to ensure clarity.

\section{Show that you care}

Showing one that you care is not simply a matter of showing up and saying "I'm here to help and this is what I'm going to do". Some of the concerns raised within the youth perspective were around not being meaningfully consulted regarding services that they were being referred to, not feeling comfortable with some interventions, and not knowing or feeling any connection to the person offering the service. Concepts of youth voice (Mitra, 2004) and the strengths-based approach (Laursen, 2000; Gilligan, 2004; Sanders \& Munford, 2005) address these concerns as they explain that showing care is about working in partnership with the young person by listening to what they have to say and what they see as their needs, then together coming up with a plan for achieving it. A better tactic to the "here I am to fix your problems" attitude then might be: First and foremost introducing ones-self, one's role (hopefully this has also been done previously by the person that made the referral), the desire to understand the young person, and the possible services on offer. As the findings highlighted the sensitivities of young people when being dealt with by professionals and their desire for respect, it is really important that in the very early stages the young person is made to feel genuinely cared for. For this reason I have included in the initial meeting the point of wanting to understand the young person. The old adage of putting oneself in another's shoes applies here. Each young person may need to be reassured of one's genuineness differently, and it may take time to learn to read them, but the effort should always be made.

Following the initial introductions and rapport building process, it is important to express a genuine desire to help the young person by first understanding how they feel services might help them and then working together to make that happen. While there may be set concerns that have to be addressed that the young person does not highlight, depending on 
the time-frame a practitioner may have to work with a young person, these can be introduced and discussed further along the track once that relationship begins to become more trusting and comfortable. This is the where the notion of an authentic relationship (Laursen, 2004; Sanders \& Munford, 2005) comes in that gives a practitioner greater scope to address the more sensitive subjects. What these authors, and the youth, seem to be saying is that showing care does not mean the approach has to be light and fluffy and avoid the concerns at hand altogether, but rather if practitioners want to be effective in fitting their service to the young person's needs they just need to first do a bit of ground work with the young person.

\section{Trust in the young person's potential for change}

In order for a young person to trust that you are genuine in your desire to help them, they need to know that you are authentic (Sanders \& Munford, 2005). The first part of authenticity has been discussed above in the notion of building a relationship of partnership. Sanders \& Munford explain that this can take time as youth may have learnt through negative experiences that adults are unreliable. For this reason they explain that part of showing authenticity is being in it for the long haul. In answer to a question I asked one of the participants regarding why she felt a certain practitioner had helped her more than others, she explained:

She told me her background and took time out of her day to see me. Like once a week or whenever I needed to see her. - Jess

By showing a willingness to commit one's time, the implication is that there is a belief that that time is being spent on something worthwhile. That is, that by being in it for the long haul there must be a belief that the young person has the potential for change. In those circumstances that time is not something the practitioner can offer, the next best thing would be to convey that concern and explain ones desire to achieve as much as possible in 
the time that is available because of the belief in their using what is available in their goals for change.

\section{Support the young person by helping them, not directing them}

Achieving this last point is really a matter of remembering that once a relationship begins to establish, care and trust (as previously explained) need to continue to be used throughout the change process. Involving the young person in the planning process is a great start but keeping them actively involved in their development is key. This is the notion of helping and not directing (Gilligan, 2004). As Sanders \& Munford (2005) have pointed out, at the end of the day it is the young person, not the professional, who has to make the change. As the youth voice is encouraged throughout the process and they begin to feel a sense of achievement in reaching the goals they set for themselves enhanced feelings of agency, belonging and competence (Gilligan, 2004; Mitra, 2004; Sandra \& Munford, 2005) can be expected to grow. In turn this will empower the young person to take charge of their own future and build a resiliency for approaching further obstacles that may come (Gilligan, 2004).

Along with concerns around not feeling heard or respected the other concerns raised within the youth perspective that can be addressed reasonably easily is that of being labelled or treated as a problem. Following the above three points would be a great start to ensuring such mistakes are not made. In addition to this is the need for appreciating the sensitivity of youth who have been through an often confusing and overwhelming maze of services (Sanders \& Munford, 2005; Beadle, 2009). The strengths-based approach comes back into play again here. Laursen (2000) explains the importance of eradicating such statements as "this person is an alcoholic" from practitioners language as they imply a limitation on a young person's ability to change. Duncan described being upset when such a statement was made about him by his case worker within an FGC. He stated that while it might be true, the 
social worker did not need to say it like that. Laursen suggests that a strengths-based approach would encourage the case-worker to change her statement to "this person has been showing alcoholic behaviours". This statement implies the possibility for change as it implies that present choices do not have to be the be all and end all of the young person's future. Making such a simple adjustment to a statement allows a practitioner to be sensitive to the feelings and self-beliefs of a young person and still remain perfectly clear about the behaviours of concern without glossing over them.

\section{Adopting a Strengths-Based Framework}

With the strengths-based approaches highlighted above giving simple yet applicable methods of addressing the concerns raised by the youth perspective it seems fair to say that the increasing call for its implementation is justified. I have proposed the use of the AI framework for addressing concerns on a national level to look at policy and procedures for overcoming some of the negative bureaucratic effects on collaboration. I also propose that the AI framework is relevant at the front-line level. Not only does Appreciative Inquiry require the necessary focus on a young person's strengths, but the 4-D cycle ensures a thorough yet simple to follow outline of carrying out the collaborative approach. The 4-D cycle is really what makes AI practical as it ensures a flexibility that allows the framework to be used at large organisational/government levels as well as at the ground level for addressing the unique needs of an individual.

Revisiting the principles behind AI highlights how it addresses many of the concerns that have been raised both by the youth perspective and within the literature when looking at improving collaborative processes. The first set of basic principles that were outlined in Cooperrider \& Srivasta's (1987) conception of AI are that it begins with appreciation, and is applicable, provocative, and collaborative. In essence, this covers the call that good youth development initiatives use a collaborative approach that is strengths-based, applicable to the 
young person, and lets go of the check-list approach by allowing participants to think outside the square. The second set of principles that Cooperrider \& Whitney (2005) later introduced further add to the potential AI has for ensuring greater outcomes within the youth sector. The second set of principles reinforce the need for the collaborative group to recognise their interdependency, encourages questioning and discussion of the stories youth and others share, and calls for action to be taken immediately as the strengthened relationship of the group creates and sustains a positive momentum.

In defining $\mathrm{AI}$ as a framework for organisational change Cooperrider \& Whitney (2005) state:

Appreciative Inquiry is about the co-evolutionary search for the best in people, their organisations, and the relevant world around them. In its broadest focus, it involves systematic discovery of what gives 'life" to a living system when it is most alive, most effective, and most constructively capable in economic, ecological, and human terms. AI involves, in a central way, the art and practice of asking questions that strengthen a system's capacity to apprehend, anticipate, and heighten positive potential. - Cooperrider \& Whitney, 2005, p. 3.

To appreciate the AI framework's potential for ensuring youth-centred collaboration within youth services the above statement can be altered, to:

Appreciative Inquiry is about the co-evolutionary search for the best in young people, their supports, and the relevant world around them. In its broadest focus, it involves systematic discovery of what gives "life" to a young person when he or she is most alive, most operative, and most productive in the various areas of his or her life. AI involves, in a central way, the art and practice of asking questions that strengthen a young person's capacity to apprehend, anticipate, and heighten their positive potential. 
Within this adjusted statement, the opportunity that AI gives to allowing a collaborative process for youth receiving intervention and development services that are strengths-based and youth-centred is clear. It addresses both of the two concerns raised by the youth perspective and highlights factors for successful collaboration as highlighted in the literature review. Furthermore, there is an implication that the AI framework can also provide collaborative benefits for professionals as outlined by Laursen (2000) and Flores (2007) as the process not only requires looking for the best in the young person but in their supports and the relevant world around them. The outcomes outlined above can only come through the proper use of the 4-D cycle guided by the principles of Appreciative Inquiry. I will outline an example of how this might work for the benefit of youth.

Beginning with discovery, the group will not only learn about the young person and what they have experienced thus far relating to their coming to the point of a collaborative intervention but the discovery will also pertain to discovering how each of the professionals and family members came to attend the meeting. Keeping in mind the principle of appreciation, as each person shares not only what brought them together but how they have felt about their experiences with involvement in youth services relationships of understanding will begin to build. Once an understanding of peoples' purpose and experiences has been established the group may feel ready to begin looking at an unconditional positive question that is centred on activating the young person's potential. Here is the opportunity that AI gives to ensuring the young person is actively involved, heard, and empowered as they participate in the process. By helping to come up with the unconditional positive question the young person will not only feel that others believe in their potential but in being part of the process they are less likely to put up resistance (Laursen 2000; Gilligan, 2004). Once the unconditional positive question has been established and the group has discovered what has been they can move into the dream phase of looking at what can be. Again, this is an opportunity for those who have a fair prior knowledge of the young person to focus on his or 
her strengths and how they might be drawn upon for realising potential. It is also an opportunity for the young person to begin to consider taking control of a future that they will feel accomplishment in. The design phase will allow the group to then consider possibilities regarding how their collective resources might be used for accomplishing the dream. Hearing what each person in the room is willing to put into the young person's dream can not only reassure the young person of the support network surrounding them but it will also ensure that unlike many of the youth I interviewed, the young person will understand the effort that is being made from various agencies and services towards their development. This means that while the young person may not see certain professionals on a regular basis and therefore build the same kind of rapport as they have with the youth worker, their appreciation and acknowledgement for that person's involvement and assistance is more likely. Finally, the destiny phase allows each participant in the collaborative to then go away and put into action efforts directed at achieving the dreams discussed. It was explained earlier in the text that the design and destiny stage were not as structured as some might expect them to be. The design stage is not necessarily coming up with a set plan of how the intervention will be carried out and therefore individuals may not go away with set tasks to fulfil before the next meeting. A next meeting may not happen. The outcome of each AI session will be completely dependent on the questions and dreams discussed. Here it can be seen again that the AI framework is structured enough to ensure a forward moving process yet flexible enough to meet individual needs. The findings showed that while some youth wanted to meet regularly with their collaborative group, others felt happy seeing them individually - AI will allow for both.

Who would be involved in the collaborative process? Participants as well as the literature (Beadle, 2009) have suggested that having a key person at the helm ensures both consistency and an initial authentic relationship so that the young person can feel at ease going into the process. This may be a core youth worker that has already built a rapport with the young person (Sanders \& Munford, 2005). The youth worker may initiate the AI process 
and all other meetings and other communications with the youth and their family. To establish who else needs to be involved in the collaborative group the youth worker would deliberate with the YP. I have found through my experience of interviewing that youth needed a fair bit of probing before really appreciating what was available to them in the way of support and services. This was possibly due to them not being given control over their own intervention before. Whatever the reason, giving them some examples of areas in their life or services to consider enabled them to make more informed decisions. With this in mind, when youth workers (or whoever the key person may be) first introduce the idea of a collaborative group with the young person they may like to have a discussion about some of the services and people that the young person might like to consider. To ensure that no service or person that might be relevant to the young person is overlooked I also wish to suggest a general guideline for approaching this discussion.

It has been said that in order for collaboration to be successful approaches need to be child-centred and culturally competent (Guthrie \& Guthrie, 1990; White \& Wehlage, 1995; Wyles, 2007). From a New Zealand perspective, Bishop (2005) has explained that cultural competence does not require multi-cultural expertise but instead an acknowledgement of whanau ties and background. Where family is generally understood as ones immediate family, whanau applies to both immediate and extended family and takes general social networks into account also. A model that more fully appreciates the meaning of whanau in relation to an individual with complex needs is Durie's (1994) Whare Tapa Wha.

Durie's (1994) Whare Tapa Wha model looks at the concept that in order for a person to have holistic wellbeing there are four key areas of life that need to be addressed. The model is explained through the imagery of a house. Essentially, a house requires four sturdy walls to stand. When one wall is not present or significantly lacking strength the house will not withstand the battering of outside influences. The four walls are: Tinana - Physical; Wairua - Spiritual; Hinengaro - Intellectual, and; Whanau - Social. 
If Durie's (1994) model is considered when working collaboratively for youth then it would seem important to ensure that each of these areas are represented in the collaborative process. Not only might this eliminate the oversight of needs to be addressed but it could allow for strengths to be recognised and used to help build up the areas that may be lacking. For example, if a particular young person is involved in a sport then when considering the different people that may be involved in that young person's physical side, the collaborative may decide that there is a sports coach with whom he or she has a good relationship and invite them to join the group. When looking at why sports is a positive aspect of the young person's life the coach will be able to share insight as to whether it has always been a positive relationship or whether certain techniques were used to achieve outcomes that might be used in other areas of the young person's life. With further reference to Laursen (2000) and Flores (2007), if the collaborative is faced with numerous challenges with this particular young person the coach may bring a refreshing strengths-based outlook that gives hope for success and a greater determination to stick it out.

This section has highlighted that along with the various professionals that have expertise and resources to bring to the table, there are many other persons or organisation who should be considered for involvement in the collaborative process when working with youth that have complex and multi-faceted needs. While such notions are spoken of broadly within the literature, there is little direct emphasis on just how such supports and networks might be discovered and brought on board. Within the New Zealand context, it would seem that Durie's (1994) model, Whare Tapa Wha, is a simple yet inclusive one to consider for ensuring a culturally competent and holistic approach that when coupled with the AI framework will allow for positive, empowering youth development. 


\section{A Possible Model: Collaboration for Youth Development within Aotearoa New Zealand}

To best illustrate how the collaborative process might look when Durie's (1994) model of Whare Tapa Wha and AI come together I have adapted Durie's model to the analogy of a large dinner table (see Figure 1). While materials may be different across the world the concept of a dinner table is somewhat universal in that it is a place where people come together to eat food and share conversation. It is a place of refilling and bonding. On occasion, the dinner table is also a place where celebrations such as birthdays, and other feats are enjoyed. This illustration represents two parts: The Setting and The Event.

\section{The Setting}

Consider the table as representing the young person. The four legs, in accordance with Durie's (1994) four walls, represent the four areas in a person's life integral to well-being: Tinana- Physical, Wairua-Spiritual, Hinengaro- Intellectual, and Whanau- Family/Social. The table top represents the young person itself. Just as each of the four areas above are necessary for well-being each of the four legs are necessary for holding the table top up. Without one leg, the table will become unstable and will not be able to reach its potential for providing a place for eating and socialising. Similarly, without one of these areas working properly in a young person's life there is less chance of the young person meeting his or her full potential.

Also worth noting is that a table would not be a table without the table top. Just as the table cannot fully function without the legs, the legs cannot function without the top but rather will collapse as individual parts. This highlights the idea of interdependency that is often spoken of in regards to collaboration. Of particular significance is that this aspect of the analogy reinforces the necessity for involving the young person in the collaborative process as they are the reason for all coming together in the first place. If the young person is not involved none of the expertise others bring to the table is worth anything because results can only be achieved with the young person on board. As was discussed earlier in this chapter, 
the young person has critical information and resources to be used for helping them to achieve their potential (Laursen, 2000; Lay, 2000; Mitra, 2004; Sanders \& Munford, 2005). By appreciating the insights that the young person brings to the table professionals and other supports are going to be more in tune with one another as they embrace a youth centred approach and work as one.

The chairs also represent the four areas of a person's life but in this part of the analogy are not attached to the table. They are separate entities. I mentioned previously that tables are sometimes used for special occasions such as birthdays. In such cases guests are often invited. The chairs represent the people in each of the areas in a young person's life that they might like to invite on board to the collaborative process. As was highlighted in the findings, every young person is unique in how they feel collaboration might best benefit them. While there will be some people who are essential to being there, as are the legs of a table, the chairs represent the flexibility of inviting others that the young person may want involved. Also worth noting, is that aside from the physical limits of space, there is no set number for how many or few chairs can represent each of the areas in the young person's life. Just as some of the older participants shared that they only felt the need for one or two support people in their collaborative team, not each side of the table needs to be represented. If the young person feels stable in their spirituality or emotional side they may not feel it is important to have somebody assisting in that area, or they may feel that their family or social worker fills that role along with others. To be clear, the presence of the leg representing Wairua is still justified, the fact that the young person does not feel the need for further support in this area simply means that the leg alone is doing enough in that area of the person's life. 


\section{The Event}

The feast that everyone has been invited to represents Appreciative Inquiry. As each invited to participate brings their experience and resources to the table, the 4-D process is now set to take place. Together the group is now ready to share in a feast of discovering and addressing the unconditional positive question, that is: the young person's potential. As eating, particularly at such events as a birthday party, is just as much a social event as it is refuelling, as the group comes together around the table they will begin to share and learn from one another through the discovery phase, focussing particularly on the birthday boy or girl and what their feats may have been over the past year or so. They will then move into discussing the young person's future and potential as the dream phase takes place. Some may begin to offer advice and resources that will help the young person to reach their goals and aspirations - this would be the design phase. Following much good food and conversation each guest will leave the party in due course but will not forget the offers they have made or the areas in which the young person might need help. It is hoped that they will determine to do what they can to help the young person achieve those dreams, even if only by providing support and encouragement. Each will look forward to the next opportunity to reconvene around the table and hear how the young person is going with the help the group has provided.

Just as a parent helps a young person prepare for a party by listening to their wishes and doing much of the organising and background work such as cooking and decorating, a parent, youth worker, or other professional (depending on the young persons preference) will advocate for the young person to ensure the collaborative process is well prepared for and carried out smoothly. Similarly, just as a concerned parent might support a child in reaching their goals by following up with friends and family on offers they have made, the youth worker may follow up with others in the collaborative on suggestions they made or resources they can provide. 


\section{Conclusion}

While it would be ideal to solely focus on the successes youth are achieving these days, statistics showing increasing violent crime being carried out by young people have highlighted the need for addressing current processes of youth intervention in New Zealand. Collaboration is an approach that has been called for in recent years due to its ability to reach the multi-faceted needs of youth-at-risk. While there is evidence of this call being heard with collaborative practices being acknowledged by the youth participants it could be more successful in ensuring youth-centeredness and empowerment. As much as youth want to be helped, they want to be heard, they want to have a say in their future, and they want to feel they are worth something. It appears that a strengths-based approach can best allow for ensuring these desires of youth.

Appreciative Inquiry is a strengths focussed approach that both meets the needs of the youth and the support for collaboration as outlined in the literature. It is a simple yet thorough framework under-which youth and their supports can come together to discover, dream, and design the destiny of the young person. Involving the young person in this process can empower them to take charge of their own future, building resilience along the way which will enable them to meet further challenges that may arise as a stronger and wiser person. To ensure the best support group is involved in the collaborative process, Durie's (1994) holistic model of well-being, Whare Tapa Wha, might be considered as a basis for discussing possible persons and services with the young person in the initial stages.

While many obstacles to good collaborative practice have been highlighted, particularly within the literature, such as bureaucracy, time and resources, there is potential for all to be overcome. Such concerns require further enquiry at a national level and suggestion has been made for how this might be carried out. Academics in the social sector have long seen the value of empirical data when addressing issues that affect people. It is time that government and other hierarchy also acknowledge the rich insights that both 
frontline workers and youth have to add to current knowledge so that policy and procedures may be less restrictive and more youth-centred. All young people have the potential to achieve much good in their lives; they simply need the support, the structure and the empowerment to do so. It is not acceptable for them to be left feeling degraded when they do receive services. Appreciative Inquiry has been successfully implemented as a framework for change for many years now and should be considered for the purpose of improving youth services and ensuring positive youth development within Aotearoa New Zealand. 


\section{References}

Atkinson, M. (2006). Interagency Collaboration in Youth Justice: Creating Change Through Action Research. The University of Waikato, Hamilton.

Bandura, A. (1964). The stormy decade: Fact or fiction? Psychology in the Schools, $1(3), 8$.

Beadle, S. (Writer) (2009). Complex solutions for complex needs [Article], Youth Studies Australia: Australian Clearinghouse for Youth Studies.

Beals, F. M. (2006). Reading Between the Lines: Representations and Constructions of Youth and Crime in Aotearoa/New Zealand. Victoria University fo Wellington, Wellington.

Bird, L., \& Drewery, W. (2000). Human Development in Aotearoa: A Journey Through Life. Auckland: McGraw-Hill Book Company New Zealand Limited.

Brofenbrenner (1979, 1986, 1995). Cited in Santrock, J. (Ed.). (1999). Life-Span Development (7 ed.): McGraw-Hill Companies Inc.

Bushe, G. (1998). Five theories of change embedded in appreciative inquiry. In D. Cooperrider, P. Sorenson, D. Whitney \& T. Yeager (Eds.), Appreciative Inquiry: An Emerging Direction for Organisation Development (pp. 117-127). Champaign, IL: Stipes.

Bushe, G. (2005). When is appreciative inquiry transformational. The Journal of Applied Behavioral Science, 41(2), 21. 
Bushe, G., \& Coetzer, G. (1995). Appreciative inquiry as a team development intervention: A controlled experiment. Journal of Applied Behavioural Science, 31(1), 18.

Camino, L. A. (2000). Youth-adult partnerships: Entering new territory in community work and research. Applied Developmental Science, 4(Suppl. 1), 9.

Centre for Social Research and Evaluation (2008). Youth Gangs in Counties Manukau.

Christchurch Social Policy Interagency Network (2003). A Collaborative Plan for Christchurch Youth 2003 -2006. Retrieved 30.11.2010. from http://www.msd.govt.nz/documents/about-msd-and-our-work/publications$\underline{\text { resources/research/children-young-people/collaborative-plan-for-christchurch-youth-2003- }}$ 2006.pdf.

Coleman, J. C. (1978). Current contradictions in adolescent theory. Journal of Youth and Adolescence, 7(1), 11.

Connolly, M. (2006). Up front and personal: Confronting dynamics in the family group conference. Family Process, 45(3), 17.

Cooperrider, D. L., \& Srivasta, S. (1987). Appreciative inquiry in organizational life. Research in Organizational Change and Development, 1, 41.

Cooperrider, D. L., \& Whitney, D. (2005). Appreciative Inquiry: A Positive Revolution in Change. CA: Berret-Koehler Publishers Inc.

Durie, M. (1994). Whaiora: Maori Health Development. Auckland: Oxford University Press. 
Erikson, E. H. (1963). Childhood and Society. London: Vintage.

Evaluation Unit of the Ministry of Social Policy (2001). Strengthening Families Interagency Case Management: Summary Analysis of Final Meeting Forms: January 2000 May 2001. Retrieved 8.12.2010. from http://www.msd.govt.nz/documents/about-msd-andour-work/publications-resources/archive/2001-summary-analysis-of-final-meeting-forms.pdf.

Fattore, T., Mason, J., \& Watson, L. (2009). Ask the children: Overview of children's understandings of well-being. Redress, 18(1), 7.

Freud, A. (1966). The Ego and the Mechanisms of Defence (Revised ed.). London: Hogarth Press.

Flyvbjerg, B. (2006). Five misunderstandings about case-study research. Qualitative Inquiry, 12(2), 28.

Gergen, K. J. (1982). Toward Transformation in Social Knowledge. NY: SpringerVerlag.

Gergen, K. J. (1994). Realities and relationships: Soundings in social construction Available from http://books.google.co.nz/books?id=tM4gVY82FpgC\&printsec=frontcover\&dq=gergen, + real

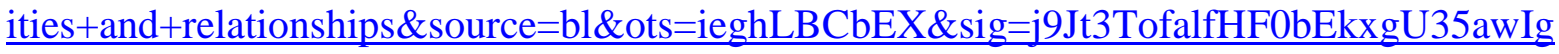
$\underline{\text { U\&hl=en\&ei=FtsGTYbDGY_dnAeqkeDIDQ\&sa=X\&oi=book_result\&ct=result\&resnum=2 }}$ $\underline{\text { \&ved }=0 \mathrm{CCMQ6AEwAQ \# v=onepage} \& \mathrm{q} \& \mathrm{f}=\text { false }}$

Gergen, K. J. (2009). An invitation to social construction Available from http://books.google.co.nz/books?id=tliSBhmSd5wC\&pg=PA81\&dq=gergen, +generative+the 
ory\&hl=en\&ei=od4GTf7AG8GinwfCq7XIDQ\&sa=X\&oi=book_result\&ct=book-

thumbnail \&resnum $=2 \& v e d=0 \mathrm{CCwQ} 6 \mathrm{wEwAQ} \# \mathrm{v}=$ onepage $\& \mathrm{q}=$ gergen $\% 2 \mathrm{C} \% 20$ generative $\%$

20theory\&f=false

Gilligan, R. (2004). Promoting resilience in child and family social work: Issues for social work practice, education and policy. Social Work Education, 23(1), 12.

Glaser, B., \& Strauss, A. (1967). The discovery of grounded theory: Strategies for qualitative research

Gluckman, P. (2010). Improving the Transition: Reducing Social and Psychological Morbidity During Adolescence. Wellington.

Guthrie, G. P., \& Guthrie, L. F. (1990). Streamlining interagency collaboration for youth at risk: Issues for educators.

Hammond, S. A., \& Royal, C. (Eds.). (2001). Lessons From the Feild: Applying Appreciative Inquiry: Thin Book Publishing Co.

Harland, A., \& Borich, A. (2007). Evaluation of Youth Offending Teams in New Zealand. from http://www.justice.govt.nz/publications/global-publications/e/evaluation-ofyouth-offending-teams-in-new-zealand-november-2007.

Head, G. (2003). Effective collaboration: Deep collaboration as an essential element to the learning process Journal of Educational Enquiry, 4(2), 16.

Hickey, D. T. (1997). Motivational and contemporary socio-constructivist instructional perspectives. Educational Psychology, 32(3), 19. 
High and Complex Needs Unit (2007). Better at Working Together: Interagency

Collaboration: Part 1, Literature review. Retrieved 27.10.2010. from

http://www.hcn.govt.nz/documents/FINAL\%20Better\%20at\%20Working\%20Together\%20P

art\%20I\%20WEB.pdf.

Hildreth, P. M., \& Kimble, C. (2002). The dualityof knowledge. Information Research, $8(1), 20$.

Hycner, R. (1985). Some guidelines for the phenomenological analysis of interview data. Human Studies, 8, 26.

Hynds, A. (2007). Navigating Unchartered Waters: Teachers Collaborating Across Difference. Victoria University of Wellington, Wellington.

Hynds, A. (2008). Developing and sustaining open communication in action research initiatives: A response to Kemmis (2006). Journal of Educational Action Research, 16(2).

Johnson, B., \& Christensen, L. (2007). Educational Research: Quantitative, Qualitative and Mixed Approaches (3rd ed.): Sage Publications Inc.

Knight, B. A., Knight, C., \& Teghe, D. (2007). Students at risk: Interagency collaboration in Queensland. Youth Studies Australia, 26(2), 8.

Laursen, E. (2000). Strengths-based practice with children in trouble. Reclaiming Children and Youth, 9(2), 6.

Lay, J. (2000). The person behind the file number. Reclaiming Children and Youth, $9(2), 2$. 
Lee, E., Mishna, F., \& Brennenstuhl, S. (2010). How to critically evaluate case-studies in social work. Research on Social Work Practice, 10, 9.

Levine, M. (2000). The family group conference in the New Zealand Children, Young Persons and Their Families Act of 1989 (CYP\&F): Review and evaluation. Behavioural Science and the Law, 18, 41.

Majumdar, D. (2006). Collaboration among government agencies with special reference to New Zealand: A literature review. Social Policy Journal of New Zealand(27), 16.

Maori Reference Group for the Taskforce for Action on Violence within Families (2009). E Tu Whanau Ora: Programme of Action for Addressing Vamily violence: 2008 2013. Retrieved 30.11.2010. from http://www.familyservices.govt.nz/documents/workingwith-us/programmes-services/whanau-ora/e-tu-whanau-ora-programme-of-action-20082013.pdf.

Ministry of Justice (2010). Child and Youth Offending Statistics: An Overview of Child and Youth Offending Statistics in New Zealand: 1992 to 2008. Statistical Bulletin. Retrieved 15.11.2010. from http://www.justice.govt.nz/publications/global-publications/c/child-andyouth-offending-statistics-in-new-zealand-1992-to2008/documents/Child_and_Youth_Offending_Statistics_1992-2008_Statistical_Bulletin.pdf.

Ministry of Social Development (1999). Strengthening families report on crosssectoral outcome measures and targets. Retrieved 8.12.2010. from http://www.msd.govt.nz/documents/about-msd-and-our-work/publicationsresources/archive/1999-strengthening-families-outcomes-report-99.pdf. 
Ministry of Social Development (2003). Mosaics: Whakaaahua Papariki: Key Findings and Good Practice for Regional Co-ordination and Integrated Service Delivery. Retrieved 8.12.2010, from http://www.msd.govt.nz/documents/about-msd-and-our-work/publicationsresources/archive/2003-mosaics.pdf.

Ministry of Social Development (2006). Family and community services Retrieved 15/07/2010, from http://www.familyservices.govt.nz/

Ministry of Social Development (2011). The Social Report 2010 Retrieved 17.05.2011, 2011, from http://www.socialreport.msd.govt.nz/

Ministry of Youth Development (2005). Youth statistics: a statistical profile of young people in New Zealand Retrieved 03.02.2011, 2011, from http://www.youthstats.myd.govt.nz/overview/purpose-of-the-resource.html

Mitra, D. L. (2004). The significance of students: can increasing "student voice" in schools lead to gains in youth development? Teachers College Record, 106(4), 38.

Monge, R. H. (1973). Developmental trends in factors of adolescent self-concept. Developmental Psychology, 8(3), 12.

National Youth Workers Network Aotearoa Inc. (2008). Code of ethics for youth work in Aotearoa New Zealand Retrieved 15/07/2010, from http://www.youthworkers.net.nz/code_of_ethics.html

New Zealand Aotearoa Adolescent Health and Development (2010). Youth development Retrieved 15/07/2010, from http://www.nzaahd.org.nz/index.php/youthdevelopment 
NZPA (2011, 11.03.2011). Teacher union funds research into national standards.

NZherald.co.nz, p. 1. Retrieved 14.03.2011, from

http://www.nzherald.co.nz/education/news/article.cfm?c_id=35\&objectid=10711713

Office of the Commissioner, New Zealand Police (2005). New Zealand Police National Youth Policing Plan 2005-2006.

Okamoto, S. K. (2001). Inter-agency collaboration with high-risk gang youth. Child and Adolescent Social Work Journal, 18(1), 17.

Organised financial crime agency of New Zealand (2010). Organised Crime in New Zealand. Retrieved 06.12.2010. from

http://www.ofcanz.govt.nz/sites/default/files/Organised-Crime-in-NZ-2010-Public-

Version.pdf.

Osborne, J. (2004). Academic disidentification: Unravelling underachievement among Black boys'. In J. Wearmouth, R. C. Richmond, T. Glynn \& M. Berryman (Eds.), Understanding Pupil Behaviour in Schools: A Diversity of Approaches (pp. 51-56). London: Fulton.

Panitz, T. (1999). The motivational benefits of cooperative learning. New Directions for Teaching and Learning, 78, 6.

Resnick, G., \& Burt, M. R. (1996). Youth at risk: Definitions and implications for service delivery. American Journal of Orthopsychiatry, 66(2), 17.

Sanders, J., \& Munford, R. (2005). Authentic relationships: Possibilities for social work to make a difference for children and young people. Childrenz Issues, 9(1), 5. 
Santrock, J. (Ed.). (1999). Life-Span Development (7 ed.): McGraw-Hill Companies Inc.

Schnellbacher, J., \& Leijssen, M. (2009). The significance of therapist genuineness from the clients perspoective Journal of Humanistic Psychology, 49(2), 23.

Spergel, I. (2005). The youth gang problem: A community approach

Spergel, I. A. (1992). Youth gangs: An essay review. Social Service Review, 66(1), 21.

Statistics New Zealand (2009). Review of Crime and Criminal Justice Statistics Report 2009. Wellington.

Steinberg, L., \& Duncan, L. (2002). Work group IV: Increasing the capacity of parents families, and adults living with adolescents to improve adolescent health outcomes. Journal of Adolescent Health, 31, 3.

Strauss, A., \& Corbin, J. (1998). Basics of Qualitative Research: Techniques and Procedures for Developing Grounded Theory (2 ed.). CA: Sage Publications, Inc.

Strengthening Families (2010). Strengthening families: whakakaha whaanau Retrieved 8.12.2010, from http://www.strengtheningfamilies.govt.nz/

Vasudevan, L., \& Campano, G. (2009). The social production of adolescent risk and the promise of adolescent literacies. Review of Research in Education, 33, 35.

Walker, A. S. (2007). The Strengthening Families strategy: An Enduring Model of Interagency Collaboration in an Era of Change. Victoria University of Wellington, Wellington. 
Walter, U. M., \& Petr, C. G. (2000). A template for family-centered interagency collaboration. Families in Society, 81(5), 10.

Wearmouth, J., Glynn, T., \& Berryman, M. (2005). Perspectives on Student Behaviour in Schools: Routledge.

Weist, M. D., Lowie, J. A., Flaherty, L. T., \& Pruitt, D. (2001). Collaboration among the education, mental health, and public health systems to promote youth mental health. Psychiatric Services, 52(10), 4.

Wheeler, W. (2000). Emerging organizational theory and the youth development organization. Applied Developmental Science, 4(Suppl. 1), 8.

White, J., \& Wehlage, G. (1995). Community collaboration: If it is such a good idea, why is it so hard to do? Educational Evaluation and Policy Analysis, 17(1), 16.

Wood, D. J., \& Gray, B. (1991). Toward a comprehensive theory of collaboration. The Journal of Applied Behavioral Science, 27(2), 25.

Wyles, P. (Writer) (2007). Success with Wraparound [Article], Youth Studies Australia: Australian Clearinghouse for Youth Studies.

Yager, S., Johnson, D. W., \& Johnson, R. T. (1985). Oral discussion, group to individual transfer, and achievement in cooperative learning groups. Journal of Educational Psychology, 77(1), 7. 
Figure 1

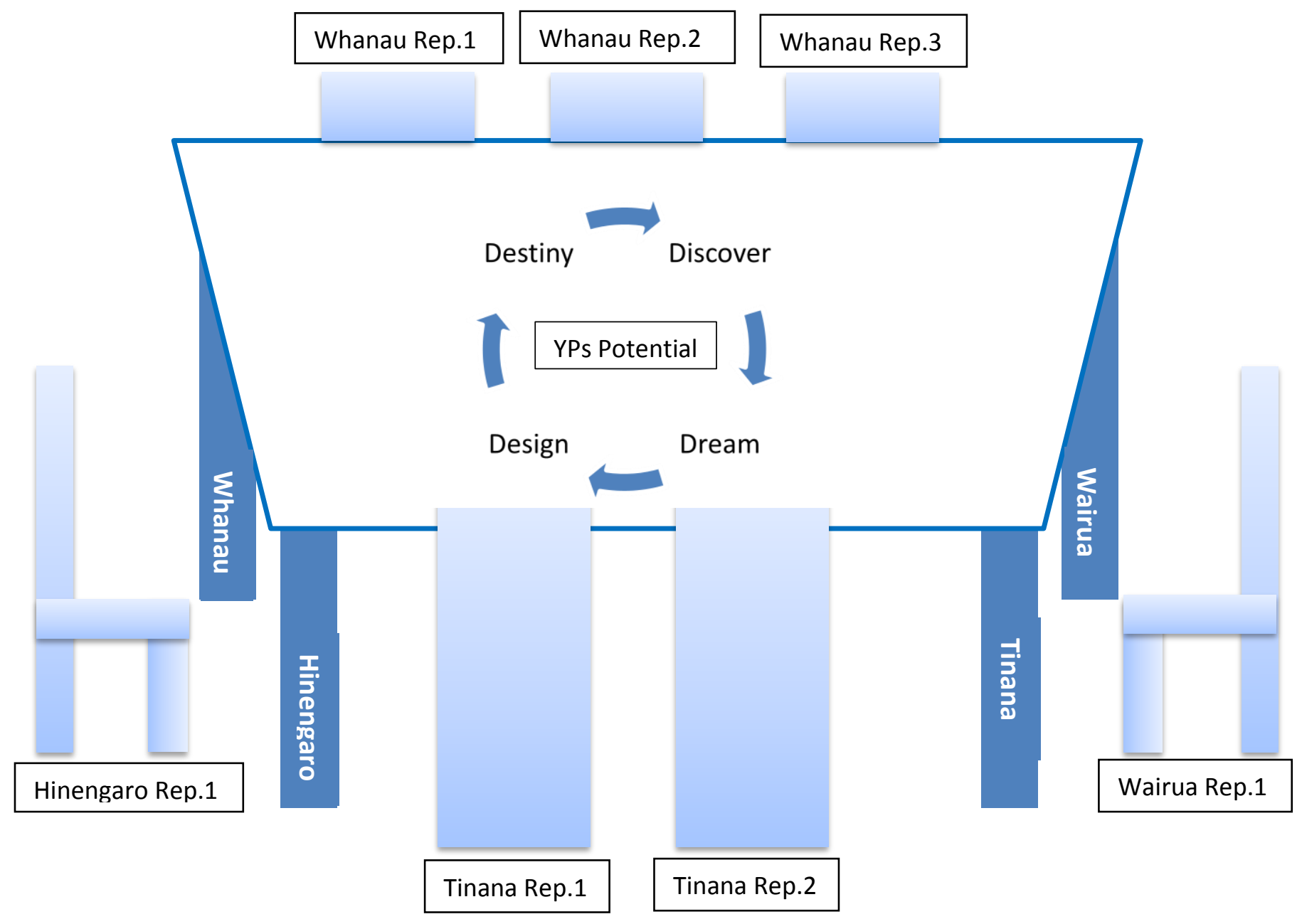


Appendix 1

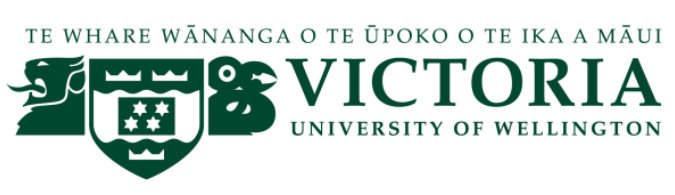

Researcher Details

Amy Lavini

Masters Candidate

Te Kura Maori

Faculty of Education

Victoria University

Wellington

Phone: 0211797267

Email: valentamy@myvuw.ac.nz
Supervisor Details

Dr Cherie Chu

Senior Lecturer

Te Kura Maori

Faculty of Education

Victoria University

Wellington

Phone: 044635316

Email: Cherie.Chu@vuw.ac.nz

\section{Participants Information Sheet}

8 October, 2010

\section{Re: A Youth perspective on Collaboration for Youth Development within Aotearoa/New Zealand}

Dear Participant,

I am a Masters student in Education at Victoria University of Wellington. As part of this degree, I am undertaking research work for my thesis. The research is looking at youths perspectives on collaboration for youth development within Aotearoa/New Zealand. I am under the supervision of Dr Cherie Chu, Senior Lecturer, the Faculty of Education, Victoria University of Wellington.

My interest in this subject comes from having previously been a youth worker in a youth development project and seeing the need for the holistic approach of collaboration to be explored further to look at ways that processes can be more effective to allow for greater outcomes for young people. While there is an increasing call for collaborative approaches to youth work, there is little research (particularly within New Zealand) to tell us how we are going. Furthermore, there is a particular gap in the literature across the globe regarding youth's experiences of whether and how a collaborative approach may or may not be working for them.

The purpose of this exploration is to provide information to contribute to improving collaborative processes within the youth sector so that interventions are more youth-centred, better implemented, and more successful. This will be achieved through a strengths-based interview framework following principles of Appreciative Inquiry. Actual organisations that youth are referred under will not be discussed, rather, the focus will be on youths understanding and experiences of collaboration and who they feel should be involved in collaborative efforts for their development. 


\section{Appendix 1 continued}

The results of this research will be written up in the form of a thesis and submitted to the Faculty of Education, Victoria University of Wellington. It is also hoped that the findings can be submitted for publishing either in an academic journal or other publications for the purpose of informing the youth sector in general. To ensure confidentiality, pseudonyms (made up names) will be used in place of participant's real names. Furthermore, recordings and notes taken during and after the research sessions will be securely stored during the writing process and then electronically wiped and destroyed after the thesis has been completed mid- 2011.

I would like to request your consent to participate in this research project through the means of a half hour interview. Participation in this research is voluntary so you should not feel obliged to consent, though your help would very much appreciated. If you agree to this request could you please sign and date the consent form attached. If you have any questions or concerns you would like to discuss before signing, or after for that matter, please feel free to call or email myself or Cherie as detailed above.

Yours sincerely,

\section{Amy Lavini}

Candidate for Masters in Education

NB. 'This research has been assessed and approved by Victoria University Faculty of Education Ethics Committee.' 
Appendix 2

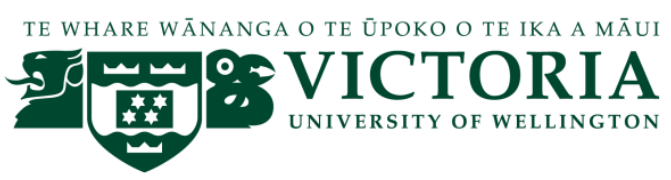

Researcher Details

Amy Lavini

Masters Candidate

Te Kura Maori

Faculty of Education

Victoria University

Wellington

Phone: 0211797267

Email: valentamy@myvuw.ac.nz
Supervisor Details

Dr Cherie Chu

Senior Lecturer

Te Kura Maori

Faculty of Education

Victoria University

Wellington

Phone: 044635316

Email: Cherie.Chu@vuw.ac.nz

\section{Participants Consent Form}

\section{Title of Research:}

A Youth perspective on Collaboration for Youth Development within Aotearoa/New Zealand

I have read the Participants Information sheet pertaining to this research project. In signing this consent form I understand the following points:

(Please tick each point to show you have read and understand)

$\bigcirc$ I agree to be interviewed by Amy Lavini regarding my experiences and thoughts on collaboration for youth development

O I may withdraw at any time from the interview.

○ The information shared in the interview will be used as data for the research project above and written up in the form of an academic thesis to be available at the Victoria University Library. It may further be published in a journal or other publication; and/or shared at academic or other professional conferences.

I will be shown the notes from any information I share and be asked to verify that it has been correctly understood and interpreted before the final work is published.

○ My details will be kept confidential in the thesis and any publications. Amy will use a pseudonym (a made up name to replace that of the participants) to protect my identity.

O At the conclusion of the research all interview notes and audio recordings will be destroyed.

Name:

Signature:

Date: 
Appendix 3

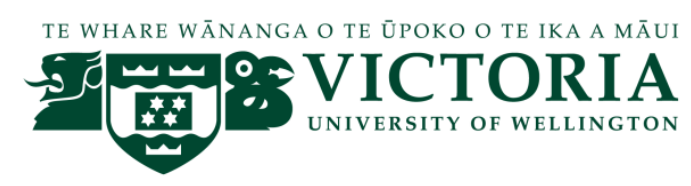

Researcher Details

Amy Lavini

Masters Candidate

Te Kura Maori

Faculty of Education

Victoria University

Wellington

Phone: 0211797267

Email: valentamy@myvuw.ac.nz
Supervisor Details

Dr Cherie Chu

Senior Lecturer

Te Kura Maori

Faculty of Education

Victoria University

Wellington

Phone: 044635316

Email: Cherie.Chu@vuw.ac.nz

\section{Parental Consent Form}

Title of Research:

A Youth perspective on Collaboration for Youth Development within Aotearoa/New Zealand

I and my child have read the Participants Information sheet pertaining to this research project. In signing this consent form I understand the following points:

(Please tick each point to show you have read and understand)

O I consent to (young person's full name)

being interviewed by Amy Lavini regarding his/her experiences and thoughts on collaboration for youth development.

O My child may withdraw at any time from the interview.

○ The information shared in the interview will be used as data for the research project above and written up in the form of an academic thesis to be available at the Victoria University Library. It may further be published in a journal or other publication; and/or shared at academic or other professional conferences.

- My child will be shown the notes from any information shared in the interview and asked to verify that it has been correctly understood and interpreted before the final work is published.

○ My child's details will be kept confidential in the thesis and any publications. Amy will use a pseudo-name (a made up name to replace that of the participants) to protect my identity.

- At the conclusion of the research all interview notes and audio recordings will be destroyed.

I, , agree to my child participating in this research.

Date: 
